\title{
Heat Capacity and Vibrational Dynamics of Poly(L-glutamic acid) ( $\alpha$ Helix)
}

\author{
Seema Srivastava, Poonam Tandon, Vishwambhar Dayal Gupta, ${ }^{\dagger}$ \\ Shantanu RASTOGI, and Chaman Mehrotra
}

Physics Department, Lucknow University, Lucknow 226 007, India

(Received May 20, 1996)

\begin{abstract}
Poly(L-glutamic acid) is one of the polyamino acids containing a bulky side chain. At the room temperature and at $\mathrm{pH}<5$ it exists in $\alpha$ helical conformation but at $\mathrm{pH}>7$ the $\alpha$ helix is reduced to the random coil state. Normal mode analysis of poly(L-glutamic acid) has been reported by Sengupta and Krimm but no phonon dispersions have been reported so far. As a consequence both the thermodynamical studies and fuller interpretation of spectra remain incomplete. In the present communication we report complete normal mode analysis and full dispersion curves for poly(L-glutamic acid). A comparative study of $\alpha$ and $\beta_{2}$ forms of poly(L-glutamic acid) has been carried out in order to identify and to understand the spectral features due to two different conformations. Heat capacity has also been calculated by using density-of-states $(g(v))$. For the calculation of normal modes the Urey Bradley force field has been used. The normal modes for $N$-deuterated systems have also been studied to check the validity of the assignments and force field. Our results are in good agreement with the observed experimental data.

KEY WORDS Poly(L-glutamic acid) / Density-of-States / Heat Capacity / Dispersion Curves /
\end{abstract}

Poly(L-glutamic acid) (PLG) is a homopolypeptide which under various conditions exists in four different conformations namely $\alpha$-helix, antiparallel pleated sheet $\left(\beta_{1}\right.$ and $\left.\beta_{2}\right)$, and random coil forms. ${ }^{1-10)}$ It has been reported by Itoh et al. ${ }^{8}$ that a temperature induced $\alpha$ helix to $\beta$-sheet transition $\left(\beta_{1}\right.$ and $\left.\beta_{2}\right)$ can be obtained. Temperature between $40^{\circ} \mathrm{C}$ to $85^{\circ} \mathrm{C}$ produces a $\beta$ form with a spacing between pleated sheets $d_{001}$ of $9.03 \AA$ termed as $\beta_{1}$ and is similar to the ordinary antiparallel pleated sheet structure. On heating further above $85^{\circ} \mathrm{C}$, $\beta_{1}$ form undergoes another conformational transition reducing the $d_{001}$ from 9.03 to $7.83 \AA$. This form is termed as $\beta_{2}$. It occurs without any significant change in the polypeptide back bone conformation and in the distance between adjacent hydrogen bonded polypeptide backbones. At the room temperature and at $\mathrm{pH}<5$ PLG exists in $\alpha$-helical conformation but at $\mathrm{pH}>7$ the $\alpha$ helix is reduced to the random coil state.

Vibrational spectroscopy plays a very important role in elucidating polymer structure. Normal mode analysis provides a better identification of various vibrational modes and unravel the information contained in the IR and Raman spectra. The dispersion curves provide a knowledge of the degree of coupling and dependence of the frequency of a given mode on the sequence length of the ordered conformation. These curves also facilitate correlation of the microscopic behaviour of a crystal with its macroscopic properties such as specific heat, enthalpy, and free energy.

Raman and IR spectroscopic studies and normal mode analysis for $\alpha$-helical poly(L-glutamic acid) have been reported by Sengupta and Krimm. ${ }^{11}$ However they have not obtained full dispersion curves and to the best of our knowledge no one else has reported them so far. As a consequence, both the thermodynamical studies and fuller interpretation of spectra remain incomplete. Further they have used only Valance force field for the

\footnotetext{
${ }^{\dagger}$ To whom all correspondence should be addressed.
}

calculation of normal modes. Thus the number of force constants used are inadequate and do not take into account full field especially the non-bonded interactions. Sengupta's calculations also suffer from a minor deficiency. In his calculations $\mathrm{COOH}$ group has been replaced by $\mathrm{COO}^{-}$group which would have little effect on the main chain modes but may influence some side chain frequencies of $\mathrm{CH}_{2}$ and $\mathrm{COOH}$ groups. ${ }^{11}$

This group has earliar reported vibrational dynamics of several polymeric systems in different conformations $\left(\alpha, \beta, \omega\right.$, and $3_{10}$ helices). ${ }^{12-23}$ In continuation of this work we report full dispersion curves and heat capacity derived from the density-of-states for $\alpha$-helical poly(Lglutamic acid). Inelastic neutron scattering (INS) spectra has been used to confirm the assignments of low frequency modes. The normal modes are calculated by using the Urey Bradley force field because it has some advantages over valence force field. ${ }^{24}$ In this force field the potential energy expression does not have quadratic cross terms. The force constants are supplemented by the repulsive forces between non-bounded atoms which simulate the van der Waals forces between them. The normal modes for $N$-deuterated systems have also been studied to check the validity of assignments and force field.

\section{THEORY}

\section{Calculation of Normal Modes}

The calculation of normal mode frequencies has been carried out according to Wilson's $G F$ matrix method ${ }^{25}$ as modified by Higgs $^{26}$ for an infinite chain using Urey Bradley-Shimanouchi force field which takes into account non-bonded interactions. The Wilson GF matrix method consists of writing the inverse kinetic energy matrix $G$ and the potential energy matrix $F$ in internal coordinates $R$. In the case of infinite isolated helical polymer, there are an infinite number of internal coordinates which lead to $G$ and $F$ matrices of infinite 
order. Due to the screw symmetry of the polymer a transformation similar to that given by Born and von Karman can be performed which reduces the infinite problem to finite dimensions. The transformation consists of defining a set of symmetry coordinates

$$
S(\delta)=\sum_{s=-\infty}^{\infty} R^{n} \exp (i s \delta)
$$

where $\delta$ is the vibrational phase difference between the corresponding modes of the adjacent residue units.

The elements of the $G(\delta)$ and $F(\delta)$ matrices have the form

$$
\begin{aligned}
& G_{i k}(\delta)=\sum_{s=-\infty}^{\infty} G_{i k}^{s} \exp (i s \delta) \\
& F_{i k}(\delta)=\sum_{s=-\infty}^{\infty} F_{i k}^{s} \exp (i s \delta)
\end{aligned}
$$

The vibrational secular equation which gives normal mode frequencies and their dispersion as a function of phase angles has the form

$$
|G(\delta) F(\delta)-\lambda(\delta) I|=0, \quad 0 \leq \delta \leq \pi
$$

The vibration frequencies $v(\delta)$ (in $\mathrm{cm}^{-1}$ ) are related to eigen values $\lambda(\delta)$ by the following relation

$$
\lambda(\delta)=4 \pi^{2} c^{2} v^{2}(\delta)
$$

For any given phase difference $\delta$ (other than $\phi$ or $\pi$ ), the $G(\delta)$ and $F(\delta)$ matrices are complex. In order to avoid the difficulties involved in handling complex numbers, methods have been devised to transform the complex matrices into equivalent real matrices by constructing suitable linear combinations of coordinates. One method of transforming a complex matrix to its real matrix equivalent is through a similarity transformation. It can be shown that any complex matrix $H=M+i N$ can be replaced by the real ones

$$
\left|\begin{array}{cc}
M & -N \\
N & M
\end{array}\right|
$$

In the present case, we can write $G(\delta)=G^{R}(\delta)+i G^{I}(\delta)$ and $F(\delta)=F^{R}(\delta)+i F^{I}(\delta)$, where $G^{R}(\delta), F^{R}(\delta), G^{I}(\delta)$, $F^{I}(\delta)$ are the real and imaginary parts of $G(\delta)$ and $F(\delta)$. The product $H(\delta)=G(\delta) F(\delta)$ becomes

$$
\begin{aligned}
H(\delta) & =\left|\begin{array}{cc}
G^{R}(\delta) & -G^{I}(\delta) \\
G^{I}(\delta) & G^{R}(\delta)
\end{array}\right| \times\left|\begin{array}{cc}
F^{R}(\delta) & -F^{I}(\delta) \\
F^{I}(\delta) & F^{R}(\delta)
\end{array}\right| \\
& =\left|\begin{array}{cc}
H^{R}(\delta) & -H^{I}(\delta) \\
H^{I}(\delta) & H^{R}(\delta)
\end{array}\right|
\end{aligned}
$$

where

$$
\begin{aligned}
& H^{R}(\delta)=G^{R}(\delta) F^{R}(\delta)-G^{I}(\delta) F^{I}(\delta) \\
& H^{I}(\delta)=G^{R}(\delta) F^{I}(\delta)+G^{I}(\delta) F^{R}(\delta)
\end{aligned}
$$

The matrix $H(\delta)$ now has dimensions $2 N \times 2 N$. The eigenvalues, therefore, occur in pairs of equal values. The difficulty of dealing with complex numbers is thus avoided.

In the present work, Urey Bradley force field has been used which takes into account both bonded and nonbonded interactions as well as internal tensions. The potential energy can be written as:

$$
\begin{aligned}
V= & \sum_{m, j, k} K_{j k}^{\prime} r_{j k}^{(m)}\left(\Delta r_{j k}^{(m)}\right)+K_{j k}\left(\Delta r_{j k}^{(m)}\right)^{2} / 2 \\
& +\sum_{m, i, j, k} H_{i j k}^{\prime} r_{i j}^{(m)} r_{j k}^{(m)}\left(\Delta \alpha_{i j k}^{(m)}\right)+H_{i j k} r_{i j}^{(m)} r_{j k}^{(m)}\left(\Delta \alpha_{i j k}^{(m)}\right)^{2} / 2 \\
& +\sum_{m, i, j, k} F_{i k}^{\prime} q_{i k}^{(m)}\left(\Delta q_{i k}^{(m)}\right)+F_{i k}\left(\Delta q_{i k}^{(m)}\right)^{2} / 2 \\
& +\sum_{j} K_{j}^{\tau}\left(\Delta \tau_{j}\right)^{2}+\sum_{j} K_{j}^{\omega}\left(\Delta \omega_{j}\right)^{2}
\end{aligned}
$$

where the symbols have their usual meaning. The primed quantities are introduced as internal tensions. Nonbonded interactions involve attraction and repulsion of atoms due to the overlap of their electron shells. These effects are usually expressed by the 6-exp or 6-12 type potentials. The tension terms are assumed to be all zero. The details concerning the evaluation of force constants and heat capacity from the density-of-states obtained from the dispersion curves are given in additional publication by the authors. ${ }^{22}$

\section{EXPERIMENTAL}

The INS for poly(L-glutamic acid) was obtained at the AMMRC, Watertown slow chopper. Its essential features are as follows: A collimated neutron beam passes through a refrigerated polycrystalline beryllium before striking the sample. The beryllium acts as a low pass filter effectively transmitting only those neutrons with 5.2 MeV. Neutrons scattered by the sample in the direction at right angles with respect to the incident beam are chopped by a rotating collimator. Their velocity and hence energy distribution is determined by measuring their flight time over a 5 meter flight path between chopper and detector on a $32 \mu \mathrm{s} 256$-channel analyzer. The data thus obtained are corrected for background, chopper transmission and detector efficiency, all of which are energy dependent. The incident beam energy is continuously monitored allowing different sets of data to be normalized to the same relative incident neutron intensity.

Assuming that a single phonon is involved in the scattering process, the neutron scattering cross section can be written as:

$$
\begin{aligned}
\sigma(\omega)= & {\left[\frac{E_{\mathrm{f}}}{E_{\mathrm{i}}}\right]^{1 / 2} \frac{\left[E_{\mathrm{i}}+E_{\mathrm{f}}-2\left(E_{\mathrm{i}} E_{\mathrm{f}}\right)^{1 / 2} \cos \phi\right]}{\omega\left[\exp \left(h \omega / k_{\mathrm{B}} T\right)-1\right]} } \\
& \times \sum_{l} a_{1}^{2} \exp \left(-2 W_{l}\right) g_{l}^{\prime \prime}(\omega)
\end{aligned}
$$

where $a_{l}$ is the incoherent scattering length of the $l$ th nucleus in the unit cell, $E_{\mathrm{f}}$ and $E_{\mathrm{i}}$ are the final and incident neutron energies, $M$ is the neutron mass, $\phi$ is the scattering angle, $\exp \left(-2 W_{l}\right)$ is the Debye-Waller factor for the $l$ th particle, $h \omega=E_{\mathrm{f}}-E_{\mathrm{i}}>0$ is the energy of the phonon from which the neutron is scattered and

$$
g_{l}^{\prime \prime}(\omega)=\frac{M}{M_{l}} \frac{v}{(2 \pi)^{3}} \sum_{j} \int d^{3} \theta\left|\hat{K} C_{j}^{1}(\theta)\right|^{2} \delta\left[\omega-\omega_{j}(\theta)\right]
$$

$\theta$ is phase difference, $C_{j}^{1}(\theta)$ is polarization vector, $M_{1}$ is the mass of the $l$ th particle, $\hat{K}=\hat{K}_{\mathrm{f}}-\hat{K}_{\mathrm{i}}$ is the momentum 
transfer, and $v$ the volume of the unit cell. For the case of a monoatomic polycrystalline sample, the sum over 1 reduces to

$$
\sum_{l} a_{l}^{2} \mathrm{e}^{-2} W_{l} g_{l}^{\prime \prime}(\omega)=a_{l}^{2} \exp \left(-2 W_{l}\right)\left(M / M_{l}\right) g(\omega),
$$

where $g(\omega)$ is the density-of-states.

The FT-IR and Raman spectra reported by Sengupta and Krimm. ${ }^{11}$ were used and in the low frequency region they were combined with the details available from the inelastic neutron scattering data.

\section{RESULTS AND DISCUSSION}

Poly(L-glutamic acid) contains 16 atoms per repeat unit which give rise to 48 dispersion curves. The vibrational frequencies are calculated for the values of $\delta$ ranging from $\phi$ to $\pi$ in steps of $.05 \pi$. The vibrations with the phase difference $\delta=0, \delta=\psi$, and $\delta=2 \psi$ are optically active, where $\psi$ is the angle of rotation about the helix axis which separates the adjacent units. Modes corresponding to $\delta=0$ and $\delta=\psi$ are infrared as well as Raman active and $\delta=2 \psi$ gives only Raman active modes.

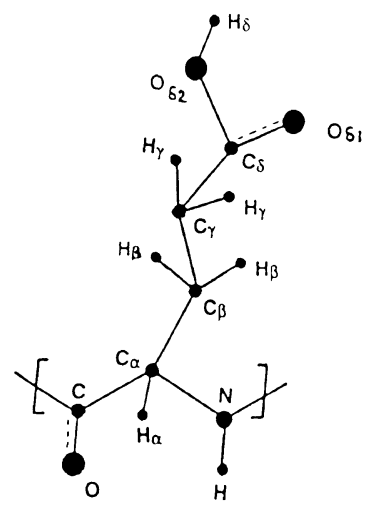

Figure 1. Chemical repeat unit of poly(L-glutamic acid).

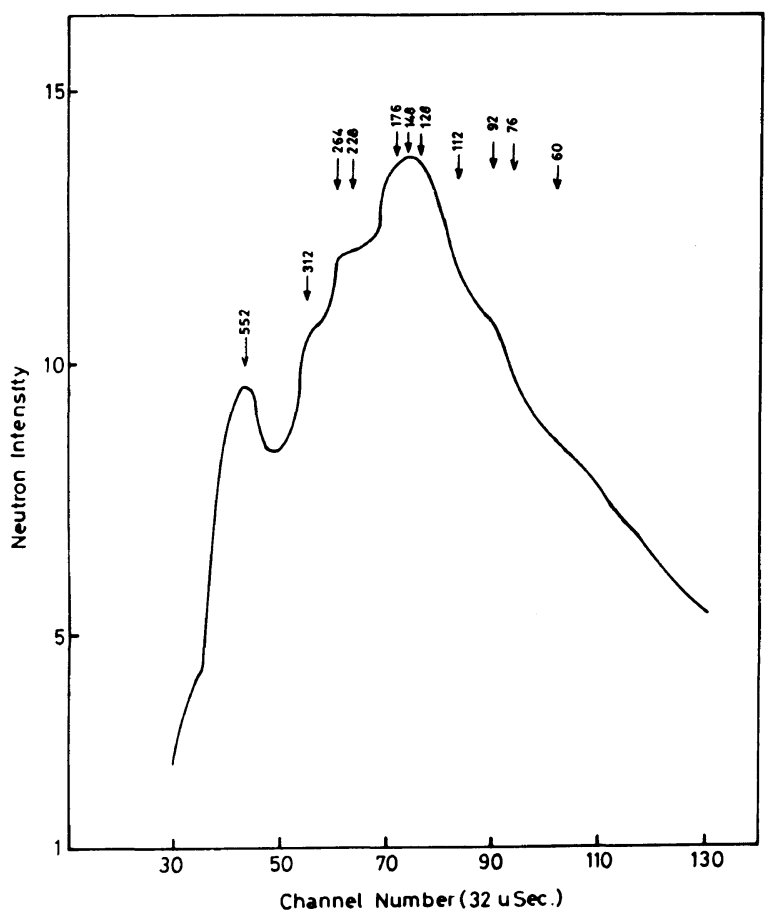

Figure 2. INS spectra of $\alpha$ poly(L-glutamic acid).
For the calculation of cartesian coordinates we have used back bone and side chain dihedral angles reported by Yan et al. ${ }^{27}$ These are $\phi=-50.5^{\circ}, \psi=-56.4^{\circ}, \chi_{1}=$ $171.8^{\circ}, \chi_{2}=289.1^{\circ}, \chi_{31}=130.7^{\circ}, \chi_{32}=-49.3^{\circ}$, and $\chi_{4}=$ $181.4^{\circ}$. The calculated frequencies at $\delta=0$ and $\delta=5 \pi / 9$ $(\psi)$ are compared with the observed frequencies. The force constants which generate the best fit are given in Table I. Since all the modes above $1300 \mathrm{~cm}^{-1}$ are nondispersive, only the modes below $1300 \mathrm{~cm}^{-1}$ are shown in the Figures 3, 4, and 5. The four zero frequencies (at

Table I. Internal coordinates and force constants (md $\left.\AA^{-1}\right)^{a}$

\begin{tabular}{|c|c|c|c|}
\hline$v(\mathbf{C}=\mathbf{N})$ & 5.73 & $\phi(\mathrm{C} \alpha-\mathrm{C}=\mathrm{N})$ & $0.200(0.60)$ \\
\hline$v(\mathrm{~N}-\mathrm{H})$ & 5.36 & $\phi(\mathrm{O}=\mathrm{C}=\mathrm{N})$ & $0.600(0.90)$ \\
\hline$v(\mathrm{~N}-\mathrm{C} \alpha)$ & 3.25 & $\phi(\mathrm{C} \alpha-\mathrm{C} \beta-\mathrm{H} \beta \alpha)$ & $0.450(0.25)$ \\
\hline$v(\mathrm{H} \alpha-\mathrm{C} \alpha)$ & 3.98 & $\phi(\mathrm{C} \alpha-\mathrm{C} \beta-\mathrm{H} \beta \beta)$ & $0.450(0.25)$ \\
\hline$v(\mathrm{C} \alpha-\mathrm{C})$ & 2.20 & $\phi(\mathrm{C} \gamma-\mathrm{C} \beta-\mathrm{H} \beta \alpha)$ & $0.450(0.25)$ \\
\hline$v(\mathrm{C}=\mathrm{O})$ & 8.21 & $\phi(\mathrm{C} \gamma-\mathrm{C} \beta-\mathrm{H} \beta \beta)$ & $0.450(0.25)$ \\
\hline$v(\mathrm{C} \alpha-\mathrm{C} \beta)$ & 3.35 & $\phi(\mathrm{C} \beta-\mathrm{C} \gamma-\mathrm{H} \gamma \alpha)$ & $0.439(0.27)$ \\
\hline$v(\mathrm{C} \beta-\mathrm{H} \beta \alpha)$ & 4.35 & $\phi(\mathrm{C} \beta-\mathrm{C} \gamma-\mathrm{H} \gamma \alpha)$ & $0.439(0.27)$ \\
\hline$v(\mathrm{C} \beta-\mathrm{H} \beta \beta)$ & 4.35 & $\phi(\mathrm{C} \delta-\mathrm{C} \gamma-\mathrm{H} \gamma \alpha)$ & $0.439(0.27)$ \\
\hline$v(\mathrm{C} \beta-\mathrm{C} \gamma)$ & 3.50 & $\phi(\mathrm{C} \delta-\mathrm{C} \gamma-\mathrm{H} \gamma \beta)$ & $0.439(0.27)$ \\
\hline$v(\mathrm{C} \gamma-\mathrm{H} \gamma \alpha)$ & 4.39 & $\phi(\mathrm{H} \beta \beta-\mathrm{C} \beta-\mathrm{H} \beta \alpha)$ & $0.368(0.30)$ \\
\hline$v(\mathbf{C} \gamma-\mathbf{H} \gamma \beta)$ & 4.39 & $\phi(\mathrm{H} \gamma \beta-\mathrm{C} \gamma-\mathrm{H} \gamma \alpha)$ & $0.363(0.27)$ \\
\hline$v(\mathrm{C} \gamma-\mathrm{C} \delta)$ & 2.85 & $\phi\left(\mathrm{C} \gamma-\mathrm{C} \delta-\mathrm{O} \delta_{2}\right)$ & $0.980(0.50)$ \\
\hline$v\left(\mathrm{C} \delta-\mathrm{O} \delta_{2}\right)$ & 6.25 & $\phi\left(\mathrm{C} \gamma-\mathrm{C} \delta=\mathrm{O} \delta_{1}\right)$ & $0.770(0.60)$ \\
\hline$v\left(\mathrm{C} \delta=\mathrm{O} \delta_{1}\right)$ & 8.85 & $\phi\left(\mathrm{O} \delta_{2}-\mathrm{C} \delta=\mathrm{O} \delta_{1}\right)$ & $0.320(0.42)$ \\
\hline$v\left(\mathrm{O} \delta_{2}-\mathrm{H} \delta\right)$ & 5.85 & $\phi\left(\mathrm{C} \delta-\mathrm{O} \delta_{2}-\mathrm{H} \delta\right)$ & $0.670(0.55)$ \\
\hline$\phi(\mathrm{C}=\mathrm{N}-\mathrm{H})$ & $0.325(0.60)$ & $\omega(\mathrm{N}-\mathrm{H})$ & 0.120 \\
\hline$\phi(C=N-C \alpha)$ & $0.700(0.35)$ & $\omega(\mathbf{C}=\mathrm{O})$ & 0.585 \\
\hline$\phi(\mathrm{H}-\mathrm{N}-\mathrm{C} \alpha)$ & $0.320(0.60)$ & $\omega\left(\mathrm{C} \delta=\mathrm{O} \delta_{1}\right)$ & 0.440 \\
\hline$\phi(\mathrm{N}-\mathrm{C} \alpha-\mathrm{C} \beta)$ & $0.550(0.50)$ & $\tau(\mathrm{N}-\mathrm{C} \alpha)$ & 0.065 \\
\hline$\phi(\mathrm{N}-\mathrm{C} \alpha-\mathrm{C})$ & $0.130(0.50)$ & $\tau(\mathrm{C}-\mathrm{C} \alpha)$ & 0.120 \\
\hline$\phi(\mathrm{C}-\mathrm{C} \alpha-\mathrm{C} \beta)$ & $0.520(0.18)$ & $\tau(\mathrm{C} \alpha-\mathrm{C} \beta)$ & 0.035 \\
\hline$\phi(\mathrm{N}-\mathrm{C} \alpha-\mathrm{H} \alpha)$ & $0.310(0.80)$ & $\tau(\mathrm{C} \beta-\mathrm{C} \gamma)$ & 0.050 \\
\hline$\phi(\mathrm{H} \alpha-\mathrm{C} \alpha-\mathrm{C} \beta)$ & $0.510(0.20)$ & $\tau(\mathrm{C} \gamma-\mathrm{C} \delta)$ & 0.050 \\
\hline$\phi(\mathrm{H} \alpha-\mathrm{C} \alpha-\mathrm{C})$ & $0.510(0.20)$ & $\tau\left(\mathrm{C} \delta-\mathrm{O} \delta_{2}\right)$ & 0.15 \\
\hline$\phi(\mathrm{C} \alpha-\mathrm{C}=\mathrm{O})$ & $0.480(0.60)$ & $\tau(\mathrm{C}=\mathrm{N})$ & 0.045 \\
\hline$\phi(\mathrm{C} \alpha-\mathrm{C} \beta-\mathrm{C} \gamma)$ & $0.750(0.22)$ & & \\
\hline$\phi(\mathrm{C} \beta-\mathrm{C} \gamma-\mathrm{C} \delta)$ & $0.850(0.22)$ & & \\
\hline
\end{tabular}

a Note: $v, \phi, \omega, \tau$ denote stretch, angle bend, wag, and torsion, respectively. Non bonded force constants are given in parentheses.

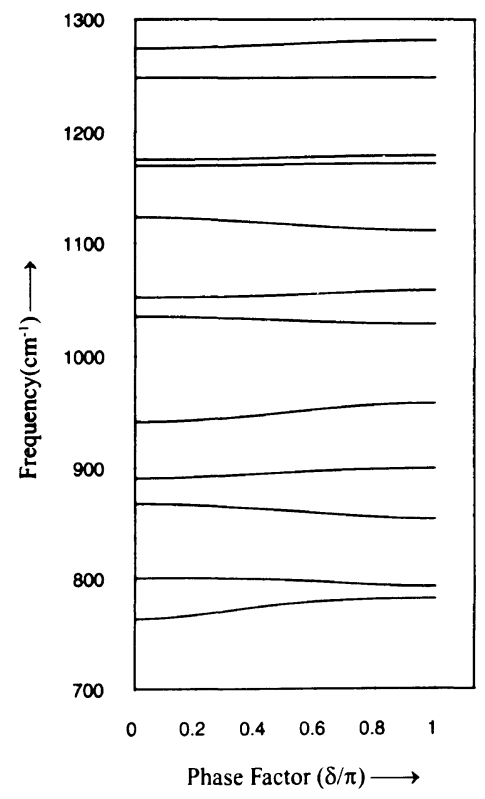

(a)

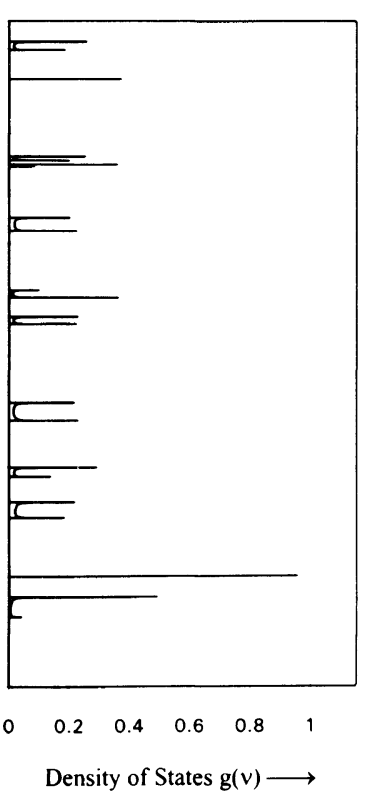

(b)
Figure 3. (a): Dispersion curves of poly(L-glutamic acid) (1300-700 $\left.\mathrm{cm}^{-1}\right)$. (b): Density-of-states $g(v)\left(1300-700 \mathrm{~cm}^{-1}\right)$. 


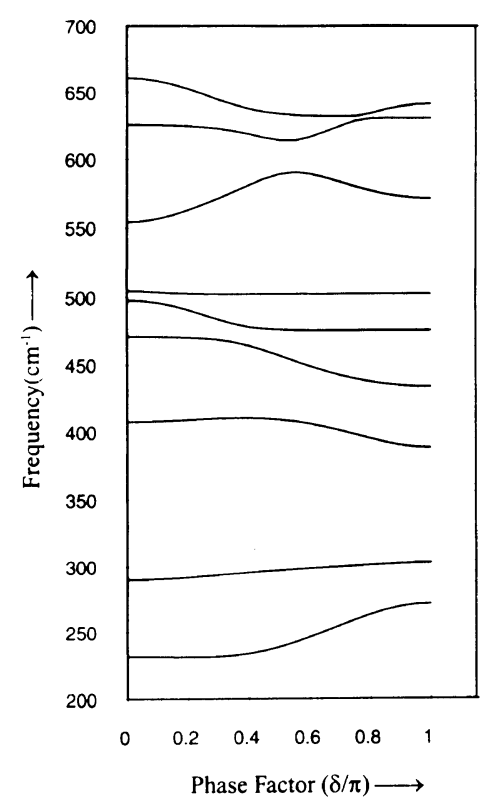

(a)

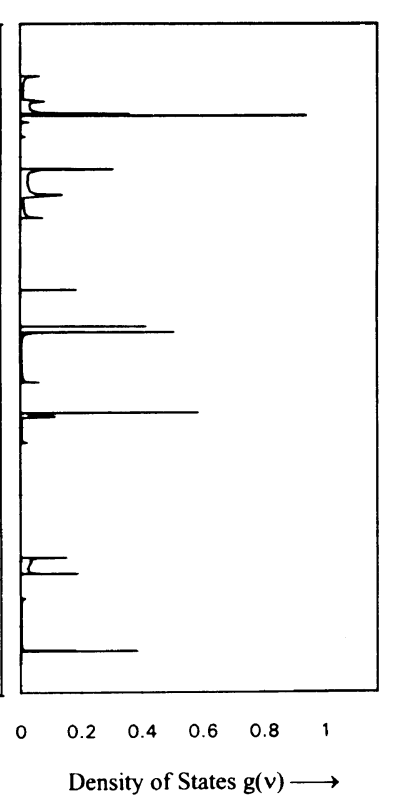

(b)
Figure 4. (a): Dispersion curves of poly(L-glutamic acid) (700-200 $\left.\mathrm{cm}^{-1}\right)$. (b): Density-of-states $g(v)\left(700-200 \mathrm{~cm}^{-1}\right)$.

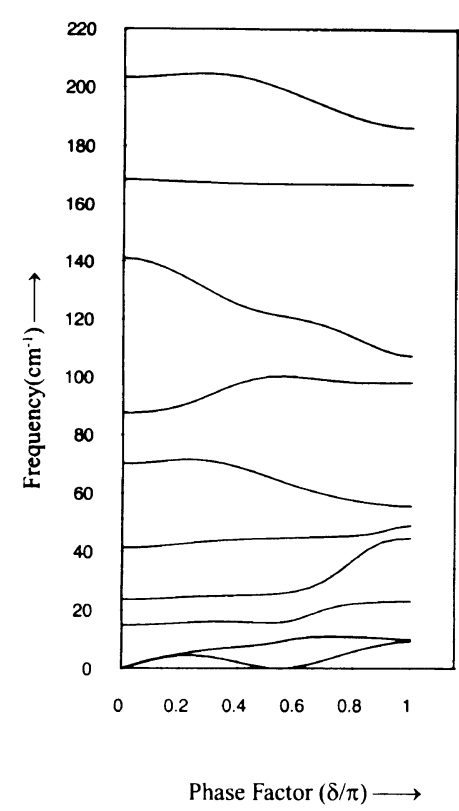

(a)

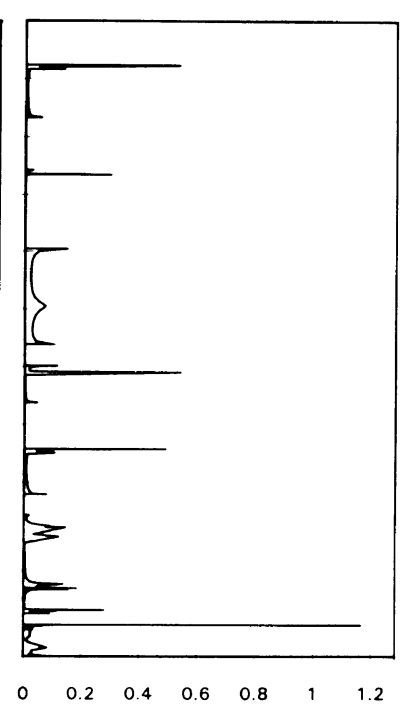

Density of States $g(v) \longrightarrow$

(b)
Figure 5. (a): Dispersion curves of poly(L-glutamic acid) below 220 $\left.\mathrm{cm}^{-1}\right)$. (b): Density-of-states $g(v)$ below $220 \mathrm{~cm}^{-1}$.

$\delta=0$ and $\delta=5 \pi / 9$ ) correspond to the acoustic modes which represent rotation about the helix axis and translations parallel and perpendicular to the helix axis. The assignments are made on the basis of P.E.D.'s for the different modes, line intensity, line profile and the presence/absence of modes in other molecules in similar environment. The assignments reported by Sengupta and $\mathrm{Krimm}^{11}$ have proved very useful in this regard. For the sake of discussion it is convenient to group the normal vibrational frequencies as back bone modes, side chain modes and mixed modes. All of these calculated modes (back bone, side chain, and mixed) together with their potential energy distribution and observed values are listed in Tables II, III, and IV, respectively.

\section{Back Bone Modes}

Modes involving the motions of the skeletal atoms are termed as back bone modes. They are given in Table II. The back bone and side chain coupled modes are given in Table IV. A comparison of various amide modes of PLG with other $\alpha$-helical polypeptides viz. poly(Lleucine), poly(L-alanine), and poly(L-valine) are given in Table V. For all the polypeptides, amide A, I, II, and III fall nearly in the same region. The amide $\mathrm{A}$ band arising due to $\mathrm{N}-\mathrm{H}$ stretching vibration is highly sensitive to the strength of $(\mathrm{N}-\mathrm{H} \cdots \mathrm{O}=\mathrm{C})$ hydrogen bond. The calculated amide $\mathrm{A}$ at $3299 \mathrm{~cm}^{-1}$ is assigned to the observed peak at $3301 \mathrm{~cm}^{-1}$ in the IR spectrum which is higher than the $\mathrm{N}-\mathrm{H}$ stretch observed in $\beta_{2}$ form $\left(3230 \mathrm{~cm}^{-1}\right){ }^{28}$ This indicates a weaker hydrogen bonding and stronger $\mathrm{N}-\mathrm{H}$ bonding in $\alpha$ helical form. This is further supported by the fact that $(\mathrm{N} \cdots \mathrm{O})$ distance in case of $\alpha$ helix is $2.72 \AA$ and in case of $\beta_{2}$ form this distance is $2.52 \AA^{3}$. On $N$-deuteration this mode is shifted to $2407 \mathrm{~cm}^{-1}$.

The vibrational modes giving rise to amide I and amide II consist of $(\mathrm{C} \cdots \mathrm{O}),(\mathrm{C} \cdots \mathrm{N})$ stretches and $(\mathrm{N}-\mathrm{H})$ in-plane-bendings respectively. These modes are calculated at $1650 \mathrm{~cm}^{-1}$ and $1544 \mathrm{~cm}^{-1}$. Amide II occurring at $1544 \mathrm{~cm}^{-1}$ is replaced by a mode at $1405 \mathrm{~cm}^{-1}$ on $\mathrm{N}$-deuteration. It corresponds to the observed peak at $1419 \mathrm{~cm}^{-1}$ in Raman spectra. ${ }^{6}$ The amide III mode which is mainly a combination of the $(\mathrm{C} \cdots \mathrm{N})$ stretch and $\mathrm{N}-\mathrm{H}$ in-plane-bendings is calculated at $1274 \mathrm{~cm}^{-1}$ and observed at $1283 \mathrm{~cm}^{-1}$ and $1296 \mathrm{~cm}^{-1}$ in IR and Raman spectra, ${ }^{11}$ respectively. With increase in the value of $\delta$, a decrease in the contribution of skeletal stretches to P.E.D. and a mixing of $\mathrm{H} \alpha$ bendings with amide III is observed. This mode is shifted to $1001 \mathrm{~cm}^{-1}$ on $N$ deuteration and can be identified with the $1006 \mathrm{~cm}^{-1}$ band in the Raman spectra. ${ }^{6}$

The mode calculated at $554 \mathrm{~cm}^{-1}$ at $\delta=0$ goes to $591 \mathrm{~cm}^{-1}$ at $\delta=5 \pi / 9$. The former is observed at $562 \mathrm{~cm}^{-1}$ in Raman, $567 \mathrm{~cm}^{-1}$ in IR and $552 \mathrm{~cm}^{-1}$ in INS. The zone end mode is assigned to the IR absorption band at $618 \mathrm{~cm}^{-1}$. The dispersion of this mode is very much like the dispersion in the $\alpha$-helices of poly(L-alanine) and poly(L-leucine) (Table V). At both the ends it contains predominantly $\omega(\mathrm{N}-\mathrm{H})$ in addition to $\tau(\mathrm{C} \cdots \mathrm{N})$ \& $\omega(\mathrm{C} \cdots \mathrm{O})$ and small contributions from other skeletal deformations. On $N$-deuteration the $\delta=0$ mode shifts down to $462 \mathrm{~cm}^{-1}$. In general the $\omega(\mathrm{N}-\mathrm{H})$ mode appears at a lower value in $\alpha$-helix than in $\beta$ form which is indicative of a relatively stronger hydrogen bond in beta. In the $\beta_{2}$ form this mode has a slight dispersion from $709 \mathrm{~cm}^{-1}$ to $713 \mathrm{~cm}^{-1}$ and both are assigned to the observed mode at $705 \mathrm{~cm}^{-1} .29$

The $763 \mathrm{~cm}^{-1}$ band is a mixture of $\omega(\mathrm{C}-\mathrm{O})(49 \%)$ and $\omega(\mathrm{N}-\mathrm{H})(17 \%)$ at $\delta=0$. This mode corresponds to $768 \mathrm{~cm}^{-1}$ in the IR spectra. Our assignment for this mode is further supported by the fact that this mode is also observed in $\alpha$ poly(L-alanine $)^{14}$ and $\alpha$ poly(L-leucine $)^{23}$ having similar \% contribution of $\mathrm{N}-\mathrm{H}$ and $\mathrm{C} \cdots \mathrm{O}$ wag. It has been observed that in case of $\alpha$ helix there is a greater mixing of $\mathrm{N}-\mathrm{H}$ and $\mathrm{C} \cdots \mathrm{O}$ wagging modes than in the $\beta_{2}$ form. This is again due to interchain hydrogen bond linkage between $\mathrm{N}-\mathrm{H}$ and $\mathrm{C} \cdots \mathrm{O}$ groups three residue apart. This brings in atoms closer within a chain 
Heat Capacity and Vibrations of $\alpha$-Poly(glutamic Acid)

Table II. Pure backbone modes

\begin{tabular}{|c|c|c|c|c|c|c|c|c|c|}
\hline Calcd & $\begin{array}{l}\text { Obsd } \\
\text { in IR }\end{array}$ & $\begin{array}{l}\text { Obsd } \\
\text { in } R\end{array}$ & \multicolumn{2}{|c|}{ Assignment ( $\%$ P.E.D. at $\delta=0.00)$} & \multirow{2}{*}{$\begin{array}{r}\text { Calcd } \\
3299\end{array}$} & \multirow{2}{*}{$\begin{array}{c}\text { Obsd } \\
\text { in IR }\end{array}$} & \multirow{2}{*}{$\begin{array}{c}\text { Obsd } \\
\text { in } \mathrm{R}\end{array}$} & \multicolumn{2}{|c|}{ Assignment ( $\%$ P.E.D. at $\delta=5 \pi / 9)$} \\
\hline 3299 & 3301 & - & $v(\mathrm{~N}-\mathrm{H})(100)$ & (Amide A) & & & & $v(\mathrm{~N}-\mathrm{H})(100)$ & (Amide A) \\
\hline 1650 & 1653 & 1652 & $v(\mathrm{C}=\mathrm{O})(59)+v(\mathrm{C}=\mathrm{N})(24)$ & (Amide I) & 1651 & 1653 & 1652 & $v(\mathrm{C}=\mathrm{O})(58)+v(\mathrm{C}=\mathrm{N})(26)$ & (Amide I) \\
\hline 1544 & 1550 & - & $\begin{array}{l}\phi(\mathrm{H}-\mathrm{N}-\mathrm{C} \alpha)(36)+\phi(\mathrm{C}=\mathrm{N}-\mathrm{H})(32) \\
+v(\mathrm{C}=\mathrm{N})(20)\end{array}$ & (Amide II) & 1540 & 1510 & - & $\begin{array}{l}\phi(\mathrm{H}-\mathrm{N}-\mathrm{C} \alpha)(38)+\phi(\mathrm{C}=\mathrm{N}-\mathrm{H})(35) \\
+v(\mathrm{C}=\mathrm{N})(14)+v(\mathrm{~N}-\mathrm{C} \alpha)(5)\end{array}$ & (Amide II) \\
\hline
\end{tabular}

a Note: All frequencies are in $\mathrm{cm}^{-1}$.

Table III. Side chain modes ${ }^{\mathrm{a}}$

\begin{tabular}{|c|c|c|c|}
\hline Calcd & $\begin{array}{l}\text { Obsd } \\
\text { in IR }\end{array}$ & $\begin{array}{l}\text { Obsd } \\
\text { in } \mathrm{R}\end{array}$ & Assignment ( $\%$ P.E.D. at $\delta=0.00)$ \\
\hline 3302 & 3301 & - & $v\left(\mathrm{O} \delta_{2}-\mathrm{H} \delta\right)(100)$ \\
\hline 2978 & - & - & $v(\mathrm{C} \gamma-\mathbf{H} \gamma \alpha)(44)+v(\mathrm{C} \gamma-\mathbf{H} \gamma \beta)(39)+v(\mathbf{C} \beta-\mathbf{H} \beta \beta)(9)+v(\mathrm{C} \beta-\mathrm{H} \beta \alpha)(8)$ \\
\hline 2968 & - & - & $v(\mathrm{C} \beta-\mathrm{H} \beta \alpha)(42)+v(\mathrm{C} \beta-\mathrm{H} \beta \beta)(40)+v(\mathbf{C} \gamma-\mathbf{H} \gamma \beta)(10)+v(\mathbf{C} \gamma-\mathbf{H} \gamma \alpha)(8)$ \\
\hline 2941 & 2939 & 2933 & $v(\mathrm{C} \gamma-\mathrm{H} \gamma \beta)(51)+v(\mathrm{C} \gamma-\mathrm{H} \gamma \alpha)(48)$ \\
\hline 2921 & - & - & $v(\mathrm{C} \beta-\mathrm{H} \beta \beta)(50)+v(\mathrm{C} \beta-\mathrm{H} \beta \alpha)(50)$ \\
\hline 1723 & 1718 & 1720 & $v\left(\mathrm{C} \delta=\mathrm{O} \delta_{1}\right)(58)+v\left(\mathrm{C} \delta-\mathrm{O} \delta_{2}\right)(20)+\phi\left(\mathrm{C} \delta-\mathrm{O} \delta_{2}-\mathrm{H} \delta\right)(8)+\phi\left(\mathrm{C} \gamma-\mathrm{C} \delta-\mathrm{O} \delta_{2}\right)(7)$ \\
\hline 1448 & 1451 & 1450 & $\phi(\mathrm{H} \beta \beta-\mathrm{C} \beta-\mathrm{H} \beta \alpha)(70)+\phi(\mathrm{C} \gamma-\mathrm{C} \beta-\mathrm{H} \beta \alpha)(7)+\phi(\mathrm{C} \gamma-\mathrm{C} \beta-\mathrm{H} \beta \beta)(5)$ \\
\hline 1425 & 1417 & 1420 & $\phi(\mathrm{H} \gamma \beta-\mathrm{C} \gamma-\mathrm{H} \gamma \alpha)(31)+\phi\left(\mathrm{C} \delta-\mathrm{O} \delta_{2}-\mathrm{H} \delta\right)(23)+v(\mathrm{C} \gamma-\mathrm{C} \delta)(16)+v\left(\mathrm{C} \delta-\mathrm{O} \delta_{2}\right)(10)+\phi(\mathrm{C} \delta-\mathrm{C} \gamma-\mathrm{H} \gamma \alpha)(8)$ \\
\hline 1418 & 1417 & 1420 & $\phi(\mathrm{H} \gamma \beta-\mathrm{C} \gamma-\mathrm{H} \gamma \alpha)(33)+\phi\left(\mathrm{C} \delta-\mathrm{O} \delta_{2}-\mathrm{H} \delta\right)(17)+v(\mathrm{C} \beta-\mathrm{C} \gamma)(9)+\phi(\mathrm{C} \beta-\mathrm{C} \gamma-\mathrm{H} \gamma \alpha)(9)+v\left(\mathrm{C} \delta-\mathrm{O} \delta_{2}\right)(5)$ \\
\hline 1248 & 1253 & - & $v\left(\mathrm{C} \delta-\mathrm{O} \delta_{2}\right)(35)+\phi\left(\mathrm{C} \delta-\mathrm{O} \delta_{2}-\mathrm{H} \delta\right)(23)+v\left(\mathrm{C} \delta=\mathrm{O} \delta_{1}\right)(16)+v(\mathrm{C} \gamma-\mathrm{C} \delta)(10)+\phi(\mathrm{C} \delta-\mathrm{C} \gamma-\mathrm{H} \gamma \beta)(5)$ \\
\hline 1170 & 1181 & 1173 & $\begin{array}{l}\phi(\mathrm{C} \alpha-\mathrm{C} \beta-\mathrm{H} \beta \beta)(23)+\phi(\mathrm{C} \delta-\mathrm{C} \gamma-\mathrm{H} \gamma \alpha)(16)+\phi(\mathrm{C} \gamma-\mathrm{C} \beta-\mathrm{H} \beta \beta)(15)+\phi(\mathrm{C} \beta-\mathrm{C} \gamma-\mathrm{H} \gamma \alpha)(18)+ \\
\phi(\mathrm{C} \alpha-\mathrm{C} \beta-\mathrm{H} \beta \alpha)(8)+\phi(\mathrm{C} \gamma-\mathrm{C} \beta-\mathrm{H} \beta \alpha)(7)+\phi(\mathrm{C} \beta-\mathrm{C} \gamma-\mathrm{H} \gamma \beta)(5)\end{array}$ \\
\hline 1035 & 1028 & 1030 & $v(\mathrm{C} \beta-\mathrm{C} \gamma)(50)+\phi(\mathrm{C} \gamma-\mathrm{C} \beta-\mathrm{H} \beta \beta)(8)+\phi(\mathrm{C} \alpha-\mathrm{C} \beta-\mathrm{H} \beta \alpha)(8)+\phi(\mathrm{C} \beta-\mathrm{C} \gamma-\mathrm{H} \gamma \alpha)(7)$ \\
\hline 498 & - & 495 & $\phi\left(\mathrm{C} \gamma-\mathrm{C} \delta=\mathrm{O} \delta_{1}\right)(41)+\omega\left(\mathrm{C} \delta=\mathrm{O} \delta_{1}\right)(14)+\phi\left(\mathrm{O} \delta_{2}-\mathrm{C} \delta=\mathrm{O} \delta_{1}\right)(9)$ \\
\hline 169 & - & - & $\tau\left(\mathrm{C} \delta-\mathrm{O} \delta_{2}\right)(93)$ \\
\hline
\end{tabular}

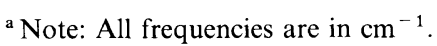

and thus enhances interatomic non-bonded interactions leading to close coupling. There is no corresponding intrachain interactions in the $\beta$ form and interchain interaction through hydrogen bonds would not show up in the calculations for an isolated chain.

The torsional motion about the peptide $(\mathrm{C} \cdots \mathrm{N})$ bond which gives rise to the amide VII band meanders over the entire chain hence it is be expected to be quite sensitive to the chain conformation. ${ }^{29}$ The calculated frequency $204 \mathrm{~cm}^{-1}$ at $\delta=0$ and $199 \mathrm{~cm}^{-1}$ at $\delta=5 \pi / 9$ can be assigned to this mode. At both the ends this mode shows considerable mixing of $\tau(\mathrm{C}-\mathrm{C} \alpha)$ and $\tau(\mathrm{N}-\mathrm{C} \alpha)$ with $\tau(\mathrm{C}-\mathrm{N})$ as in case of poly(L-alanine $)^{14}$ and poly(Lleucine). ${ }^{23}$ The dispersion of the amide VII torsional mode in the two forms of poly(L-glutamic acid) is found to be quite different. While the curves for the $\alpha$ form moves down as one goes to $\delta=5 \pi / 9$ whereas for the $\beta_{2}$ form moves up. How this is related to the nature of interaction is difficult to comment at this stage. The mode dispersing upwards has PED $\tau(\mathrm{C}-\mathrm{C} \alpha)(10)+$ $\tau(\mathrm{C} \alpha-\mathrm{C} \beta)(18)+\tau(\mathrm{C} \gamma-\mathrm{C} \delta)(27)+\phi(\mathrm{N}-\mathrm{C} \alpha-\mathrm{C})(7)+\phi(\mathrm{N} \cdots$ $\mathrm{C}-\mathrm{C} \alpha)(7)+\tau(\mathrm{C} \cdots \mathrm{N})(6)$ whereas the mode moving downwards has PED $\tau(\mathrm{C}-\mathrm{C} \alpha)(4)+\tau(\mathrm{N}-\mathrm{C} \alpha)(5)+\phi(\mathrm{N}-$ $\mathrm{C} \alpha-\mathrm{C})(11)+\phi(\mathrm{N}-\mathrm{C} \alpha-\mathrm{C} \beta)(6)+\tau(\mathrm{C}-\mathrm{N})(4)+\phi(\mathrm{C} \alpha-\mathrm{C} \cdots$ $\mathrm{N})(6)+\phi(\mathrm{C}-\mathrm{C} \alpha-\mathrm{C} \beta)(13)+\phi(\mathrm{C} \alpha-\mathrm{C} \beta-\mathrm{C} \gamma)(20)$.

The mode calculated at $891 \mathrm{~cm}^{-1}$ at $\delta=0$ and $896 \mathrm{~cm}^{-1}$ at $\delta=5 \pi / 9$ has been assigned to the characteristic mode of $\alpha$-helix. ${ }^{30}$ It is observed at $896 \mathrm{~cm}^{-1}$ in IR. ${ }^{11}$ At both the ends it has been calculated as a mixture of skeletal deformations, stretches and $\mathrm{CH}_{2}$ rocking. In case of poly $(\gamma$-benzyl-L-aspartate) poly(L-leucine), and poly(Llysine) it occurse at 931,931 , and $945 \mathrm{~cm}^{-1}$, respecPolym. J., Vol. 29, No. 1, 1997 tively. ${ }^{29}$ On $N$-deuteration the $896 \mathrm{~cm}^{-1}$ mode shifts down to $884 \mathrm{~cm}^{-1}$. This shifting is not very large because (N-D) mixing is very small in P.E.D.

\section{Side Chain Modes}

The side chain of poly(L-glutamic acid) consist of two $\mathrm{CH}_{2}$ groups at $\alpha$ and $\beta$ positions and one $\mathrm{COOH}$ group attached at the $\gamma$ position. Pure side chain modes are given in Table III. $(\mathrm{O}-\mathrm{H})$ stretch mode of $\mathrm{COOH}$ group is obtained in the same general region as $(\mathrm{N}-\mathrm{H})$ stretch. Calculated value of this mode is $3302 \mathrm{~cm}^{-1}$ which is lower than the frequency of free $(\mathrm{O}-\mathrm{H})$ group that occurs around $3500 \mathrm{~cm}^{-1}$. It is clear from the interatomic distances that there is no possibility of intrahelix hydrogen bonds between $\mathrm{OH}$ groups in the side chains. Hence the lowering of this frequency can be attributed to hydrogen bonding between the pairs of carboxylic groups which belong to different neighbouring sheets. This interhelix hydrogen bonding plays an important role in stabilising the 3D structure of $\alpha$ helices in poly(L-glutamic acid). ${ }^{9}$ Infrared spectra of polyaminoacids exhibits a strong band within the range 1720 to $1740 \mathrm{~cm}^{-1}$ assigned to the $\mathrm{C}=\mathrm{O}$ stretching vibration of the carboxylic group. ${ }^{10}$ In our calculations the corresponding mode is obtained at $1718 \mathrm{~cm}^{-1}$ which increases to $1732 \mathrm{~cm}^{-1}$ in going from $\alpha$ helix to $\beta$ sheet conformation. In both the forms it is a nondispersive mode. $\mathrm{C}_{\beta} \mathrm{H}_{2}$ and $\mathrm{C}_{\gamma} \mathrm{H}_{2}$ scissoring modes are calculated at 1448 and $1418 \mathrm{~cm}^{-1}$, and observed at 1451 and 1417 $\mathrm{cm}^{-1}$, respectively. The other mode calculated $1426 \mathrm{~cm}^{-1}$ is a mixture of $\left(\mathrm{C} \delta-\mathrm{O} \delta_{2}-\mathrm{H} \delta\right)$ bending, $\mathrm{C}_{\gamma} \mathrm{H}_{2}$ scissor and side chain stretches. There is no corresponding observed 
Table IV. Mix modes ${ }^{a}$

\begin{tabular}{|c|c|c|c|c|c|c|c|}
\hline Calcd & $\begin{array}{l}\text { Obsd. } \\
\text { in IR }\end{array}$ & $\begin{array}{l}\text { Obsd. } \\
\text { in } \mathrm{R}\end{array}$ & Assignment ( $\%$ P.E.D. at $\delta=0.00$ ) & Calcd & $\begin{array}{l}\text { Obsd. } \\
\text { in IR }\end{array}$ & $\begin{array}{l}\text { Obsd. } \\
\text { in R }\end{array}$ & Assignment ( $\%$ P.E.D. at $\delta=5 \pi / 9$ ) \\
\hline 1396 & 1388 & - & $\begin{array}{l}v(\mathrm{C} \alpha \mathrm{C} \beta)(19)+\phi(\mathrm{N}-\mathrm{C} \alpha-\mathrm{H} \alpha)(14)+\phi(\mathrm{H} \alpha \mathrm{C} \alpha-\mathrm{C} \beta)(14)+ \\
\phi(\mathrm{C} \alpha-\mathrm{C} \beta-\mathrm{H} \beta \beta)(7)+\phi(\mathrm{C} \gamma-\mathrm{C} \beta-\mathrm{H} \beta \alpha)(7)+\phi(\mathrm{C} \alpha-\mathrm{C} \beta-\mathrm{H} \beta \alpha)(7)+ \\
\phi(\mathrm{C} \gamma-\mathrm{C} \beta-\mathrm{H} \beta \beta)(6)+v(\mathrm{C} \beta-\mathrm{C} \gamma)(6)+\phi(\mathrm{H} \gamma \beta-\mathrm{C} \gamma-\mathrm{H} \gamma \alpha)(5)\end{array}$ & 1395 & 1388 & - & $\begin{array}{l}v(\mathrm{C} \alpha-\mathrm{C} \beta)(20)+\phi(\mathrm{H} \alpha-\mathrm{C} \alpha-\mathrm{C} \beta)(14)+\phi(\mathrm{N}-\mathrm{C} \alpha-\mathrm{H} \alpha)(13)+ \\
\phi(\mathrm{C} \alpha-\mathrm{C} \beta-\mathrm{H} \beta \beta)(9)+\phi(\mathrm{C} \gamma-\mathrm{C} \beta-\mathrm{H} \beta \alpha)(7)+\phi(\mathrm{C} \alpha-\mathrm{C} \beta-\mathrm{H} \beta \alpha)(7)+ \\
\phi(\mathrm{C} \gamma-\mathrm{C} \beta-\mathrm{H} \beta \beta)(7)+v(\mathrm{C} \beta-\mathrm{C} \gamma)(6)+\phi(\mathrm{H} \gamma \beta-\mathrm{C} \gamma-\mathrm{H} \gamma \alpha)(5)\end{array}$ \\
\hline 1347 & 1343 & 1340 & $\begin{array}{l}\phi(\mathrm{H} \alpha-\mathrm{C} \alpha-\mathrm{C})(32)+\phi(\mathrm{H} \alpha-\mathrm{C} \alpha-\mathrm{C} \beta)(13)+v(\mathrm{~N}-\mathrm{C} \alpha)(7)+ \\
v(\mathrm{C}=\mathrm{O})(6)+\phi(\mathrm{N}-\mathrm{C} \alpha-\mathrm{H} \alpha)(5)\end{array}$ & 1350 & 1343 & 1340 & $\begin{array}{l}\phi(\mathrm{H} \alpha-\mathrm{C} \alpha-\mathrm{C})(25)+\phi(\mathrm{H} \alpha-\mathrm{C} \alpha-\mathrm{C} \beta)(10)+v(\mathrm{C} \alpha-\mathrm{C})(10)+ \\
v(\mathrm{~N}-\mathrm{C} \alpha)(9)+v(\mathrm{C}=\mathrm{N})(6)+\phi(\mathrm{N}-\mathrm{C} \alpha-\mathrm{H} \alpha)(5)\end{array}$ \\
\hline 1334 & 1343 & 1340 & $\begin{array}{l}\phi(\mathrm{N}-\mathrm{C} \alpha-\mathrm{H} \alpha)(24)+\phi\left(\mathrm{C} \delta-\mathrm{O} \delta_{2}-\mathrm{H} \delta\right)(10)+ \\
\phi(\mathrm{C} \delta-\mathrm{C} \gamma-\mathrm{H} \gamma \beta)(10)+v(\mathrm{C} \beta-\mathrm{C} \gamma)(9)+\phi(\mathrm{C} \beta-\mathrm{C} \gamma-\mathrm{H} \gamma \alpha)(8)+ \\
\phi(\mathrm{H} \alpha \mathrm{C} \alpha-\mathrm{C})(8)+\phi(\mathrm{C} \delta \mathrm{C} \gamma-\mathrm{H} \gamma \alpha)(7)+\phi(\mathrm{C} \beta-\mathrm{C} \gamma-\mathrm{H} \gamma \beta)(6)\end{array}$ & 1334 & 1343 & 1340 & $\begin{array}{l}\phi(\mathrm{N}-\mathrm{C} \alpha-\mathrm{H} \alpha)(20)+\phi\left(\mathrm{C} \delta-\mathrm{O} \delta_{2}-\mathrm{H} \delta\right)(11)+\phi(\mathrm{C} \delta-\mathrm{C} \gamma-\mathrm{H} \gamma \beta)(11)+ \\
v(\mathrm{C} \beta-\mathrm{C} \gamma)(9)+\phi(\mathrm{C} \beta-\mathrm{C} \gamma-\mathrm{H} \gamma \alpha)(9)+\phi(\mathrm{C} \beta-\mathrm{C} \gamma-\mathrm{H} \gamma \beta)(7)+ \\
\phi(\mathrm{C} \delta-\mathrm{C} \gamma-\mathrm{H} \gamma \alpha)(7)+\phi(\mathrm{H} \alpha-\mathrm{C} \alpha-\mathrm{C})(6)\end{array}$ \\
\hline 1316 & 1313 & 1310 & $\begin{array}{l}\phi(\mathrm{N}-\mathrm{C} \alpha-\mathrm{H} \alpha)(23)+\phi(\mathrm{H} \alpha-\mathrm{C} \alpha-\mathrm{C} \beta)(13)+\phi(\mathrm{C} \gamma-\mathrm{C} \beta-\mathrm{H} \beta \alpha)(12)+ \\
\phi(\mathrm{C} \beta-\mathrm{C} \gamma-\mathrm{H} \gamma \beta)(10)+\phi(\mathrm{C} \alpha-\mathrm{C} \beta-\mathrm{H} \beta \alpha)(8)+\phi(\mathrm{C} \delta-\mathrm{C} \gamma-\mathrm{H} \gamma \beta)(6)+ \\
\phi(\mathrm{C} \alpha-\mathrm{C} \beta-\mathrm{H} \beta \beta)(6)+\phi\left(\mathrm{C} \delta-\mathrm{O} \delta_{2}-\mathrm{H} \delta\right)(5)+\phi(\mathrm{C} \gamma-\mathrm{C} \beta-\mathrm{H} \beta \beta)(5)\end{array}$ & 1316 & 1313 & 1310 & $\begin{array}{l}\phi(\mathrm{N}-\mathrm{C} \alpha-\mathrm{H} \alpha)(28)+\phi(\mathrm{H} \alpha-\mathrm{C} \alpha-\mathrm{C} \beta)(11)+\phi(\mathrm{C} \gamma-\mathrm{C} \beta-\mathrm{H} \beta \alpha)(11)+ \\
\phi(\mathrm{C} \beta-\mathrm{C} \gamma-\mathrm{H} \gamma \beta)(10)+\phi(\mathrm{C} \alpha-\mathrm{C} \beta-\mathrm{H} \beta \alpha)(7)+\phi(\mathrm{C} \alpha-\mathrm{C} \beta-\mathrm{H} \beta \beta)(6)+ \\
\phi(\mathrm{C} \delta-\mathrm{C} \gamma-\mathrm{H} \gamma \beta)(5)+\phi(\mathrm{C} \gamma-\mathrm{C} \beta-\mathrm{H} \beta \beta)(5)+\phi\left(\mathrm{C} \delta-\mathrm{O} \delta_{2}-\mathrm{H} \delta\right)(5)\end{array}$ \\
\hline 1274 & 1283 & 1296 & $\begin{array}{l}v(\mathrm{C}=\mathrm{N})(28)+v(\mathrm{C} \alpha-\mathrm{C})(14)+v(\mathrm{C}=\mathrm{O})(11)+\phi(\mathrm{H}-\mathrm{N}-\mathrm{C} \alpha)(10) \\
v(\mathrm{~N}-\mathrm{C} \alpha)(9)+\phi(\mathrm{O}=\mathrm{C}=\mathrm{N})(7)+\phi(\mathrm{C}=\mathrm{N}-\mathrm{H})(6) \quad \text { (Amide III) }\end{array}$ & 1279 & 1283 & 1296 & $\begin{array}{l}v(\mathrm{C}=\mathrm{N})(20)+v(\mathrm{C}=\mathrm{O})(15)+v(\mathrm{C} \alpha-\mathrm{C})(10)+\phi(\mathrm{H} \alpha-\mathrm{C} \alpha-\mathrm{C})(9) \\
\phi(\mathrm{H}-\mathrm{N}-\mathrm{C} \alpha)(9)+v(\mathrm{~N}-\mathrm{C} \alpha)(6)+\phi(\mathrm{H} \alpha-\mathrm{C} \alpha-\mathrm{C} \beta)(7)+ \\
\phi(\mathrm{O}=\mathrm{C}=\mathrm{N})(6)+\phi(\mathrm{C}=\mathrm{N}-\mathrm{H})(5)\end{array}$ \\
\hline 1176 & 1181 & 1178 & $\begin{array}{l}\phi(\mathrm{C} \beta-\mathrm{C} \gamma-\mathrm{H} \gamma \alpha)(16)+\phi(\mathrm{C} \gamma-\mathrm{C} \beta-\mathrm{H} \beta \beta)(13)+\phi(\mathrm{C} \alpha-\mathrm{C} \beta-\mathrm{H} \beta \alpha)(12)+ \\
\phi(\mathrm{C} \beta-\mathrm{C} \gamma-\mathrm{H} \gamma \beta)(11)+\phi(\mathrm{C} \gamma-\mathrm{C} \beta-\mathrm{H} \beta \alpha)(11)+\phi(\mathrm{C} \delta-\mathrm{C} \gamma-\mathrm{H} \gamma \beta)(10)+ \\
\phi(\mathrm{C} \delta-\mathrm{C} \gamma-\mathrm{H} \gamma \alpha)(6)\end{array}$ & 1178 & 1181 & 1178 & $\begin{array}{l}\phi(\mathrm{C} \gamma-\mathrm{C} \beta-\mathrm{H} \beta \beta)(19)+\phi(\mathrm{C} \alpha-\mathrm{C} \beta-\mathrm{H} \beta \beta)(18)+\phi(\mathrm{C} \alpha-\mathrm{C} \beta-\mathrm{H} \beta \alpha)(17)+ \\
\phi(\mathrm{C} \gamma-\mathrm{C} \beta-\mathrm{H} \beta \alpha)(16)+v(\mathrm{~N}-\mathrm{C} \alpha)(5)\end{array}$ \\
\hline 1123 & 1118 & 1117 & $v(\mathrm{~N}-\mathrm{C} \alpha)(47)+v(\mathrm{C} \alpha-\mathrm{C})(18)$ & 1116 & 1118 & 1117 & $\begin{array}{l}v(\mathrm{~N}-\mathrm{C} \alpha)(43)+v(\mathrm{C} \alpha-\mathrm{C})(9)+v(\mathrm{C}=\mathrm{N})(7)+\phi(\mathrm{C} \gamma-\mathrm{C} \beta-\mathrm{H} \beta \beta)(5)+ \\
\phi(\mathrm{N}-\mathrm{C} \alpha-\mathrm{C} \beta)(5)\end{array}$ \\
\hline 1052 & 1060 & 1057 & $\begin{array}{l}v(\mathrm{C} \alpha-\mathrm{C} \beta)(42)+\phi(\mathrm{H} \alpha-\mathrm{C} \alpha-\mathrm{C} \beta)(9)+\phi(\mathrm{C} \delta-\mathrm{C} \gamma-\mathrm{H} \gamma \alpha)(7)+ \\
\phi(\mathrm{C} \alpha-\mathrm{C} \beta-\mathrm{H} \beta \beta)(6)\end{array}$ & 1054 & 1060 & 1057 & $\begin{array}{l}v(\mathrm{C} \alpha-\mathrm{C} \beta)(41)+\phi(\mathrm{H} \alpha-\mathrm{C} \alpha-\mathrm{C} \beta)(9)+v(\mathrm{~N}-\mathrm{C} \alpha)(6)+ \\
\phi(\mathrm{C} \delta-\mathrm{C} \gamma-\mathrm{H} \gamma \alpha)(5)+\phi(\mathrm{C} \alpha-\mathrm{C} \beta-\mathrm{H} \beta \beta)(5)\end{array}$ \\
\hline 941 & 928 & 924 & $\begin{array}{l}\phi(\mathrm{C} \alpha-\mathrm{C} \beta-\mathrm{H} \beta \alpha)(12)+v(\mathrm{C} \gamma-\mathrm{C} \delta)(10)+\phi(\mathrm{C} \gamma-\mathrm{C} \beta-\mathrm{H} \beta \alpha)(8)+ \\
\phi(\mathrm{C} \gamma-\mathrm{C} \beta-\mathrm{H} \beta \beta)(8)+\phi(\mathrm{C} \alpha-\mathrm{C} \beta-\mathrm{H} \beta \beta)(7)+v(\mathrm{C} \alpha-\mathrm{C})(6)+ \\
\phi(\mathrm{C} \beta-\mathrm{C} \gamma-\mathrm{C} \delta)(5)+v(\mathrm{C}=\mathrm{N})(5)\end{array}$ & 951 & - & - & $\begin{array}{l}\phi(\mathrm{C} \gamma-\mathrm{C} \beta-\mathrm{H} \beta \alpha)(10)+v(\mathrm{C} \alpha-\mathrm{C})(10)+\phi(\mathrm{C} \alpha-\mathrm{C} \beta-\mathrm{H} \beta \beta)(10)+ \\
\phi(\mathrm{C} \alpha-\mathrm{C} \beta-\mathrm{H} \beta \alpha)(9)+v(\mathrm{C} \gamma-\mathrm{C} \delta)(8)+\phi(\mathrm{C} \gamma-\mathrm{C} \beta-\mathrm{H} \beta \beta)(7)+ \\
v(\mathrm{C}=\mathrm{N})(5)\end{array}$ \\
\hline 891 & 896 & - & $\begin{array}{l}\phi(\mathrm{C} \delta-\mathrm{C} \gamma-\mathrm{H} \gamma \alpha)(11)+\phi(\mathrm{O}=\mathrm{C}=\mathrm{N})(9)+\phi(\mathrm{C} \beta-\mathrm{C} \gamma-\mathrm{H} \gamma \beta)(9)+ \\
\phi(\mathrm{C}=\mathrm{N}-\mathrm{C} \alpha)(9)+v(\mathrm{C} \alpha-\mathrm{C})(7)+\phi(\mathrm{C} \alpha-\mathrm{C} \beta-\mathrm{H} \beta \beta)(6)+ \\
v(\mathrm{C} \gamma-\mathrm{C} \delta)(6)+\phi(\mathrm{C} \beta-\mathrm{C} \gamma-\mathrm{H} \gamma \alpha)(6)\end{array}$ & 896 & 896 & - & $\begin{array}{l}\phi(\mathrm{C} \delta-\mathrm{C} \gamma-\mathrm{H} \gamma \beta)(11)+\phi(\mathrm{C} \beta-\mathrm{C} \gamma-\mathrm{H} \gamma \beta)(10)+v(\mathrm{C} \alpha-\mathrm{C})(8)+ \\
\phi(\mathrm{C} \beta-\mathrm{C} \gamma-\mathrm{H} \gamma \alpha)(7)+\omega\left(\mathrm{C} \delta=\mathrm{O} \delta_{1}\right)(6)+v(\mathrm{C} \gamma-\mathrm{C} \delta)(6)+ \\
\phi(\mathrm{C} \delta-\mathrm{C} \gamma-\mathrm{H} \gamma \alpha)(6)+\phi(\mathrm{O}=\mathrm{C}=\mathrm{N})(6)+\phi(\mathrm{C} \beta-\mathrm{C} \gamma-\mathrm{C} \delta)(5)+ \\
\phi(\mathrm{C}=\mathrm{N}-\mathrm{C} \alpha)(5)+\phi(\mathrm{C} \alpha-\mathrm{C} \beta-\mathrm{H} \beta \alpha)(5)\end{array}$ \\
\hline 866 & 869 & 874 & $\begin{array}{l}v(\mathrm{C} \alpha-\mathrm{C})(17)+\phi(\mathrm{C} \beta-\mathrm{C} \gamma-\mathrm{H} \gamma \beta)(14)+\omega\left(\mathrm{C} \delta=\mathrm{O} \delta_{1}\right)(9)+ \\
\phi(\mathrm{C} \delta-\mathrm{C} \gamma-\mathrm{H} \gamma \beta)(9)+\phi(\mathrm{C} \beta-\mathrm{C} \gamma-\mathrm{H} \gamma \alpha)(7)+\phi(\mathrm{C} \beta-\mathrm{C} \gamma-\mathrm{C} \delta)(6)+ \\
v(\mathrm{C} \gamma-\mathrm{C} \delta)(5)\end{array}$ & 860 & 669 & 874 & $\begin{array}{l}v(\mathrm{C} \alpha-\mathrm{C})(12)+v(\mathrm{C} \gamma-\mathrm{C} \delta)(12)+\phi(\mathrm{C} \beta-\mathrm{C} \gamma-\mathrm{H} \gamma \beta)(11)+ \\
\phi(\mathrm{C} \delta-\mathrm{C} \gamma-\mathrm{H} \gamma \alpha)(8)+v(\mathrm{C} \alpha-\mathrm{C} \beta)(6)+\omega(\mathrm{C}=\mathrm{O})(5)+ \\
\phi(\mathrm{C} \beta-\mathrm{C} \gamma-\mathrm{H} \gamma \alpha)(5)\end{array}$ \\
\hline 800 & 810 & - & $\begin{array}{l}v(\mathrm{C} \gamma-\mathrm{C} \delta)(31)+\phi(\mathrm{C} \gamma-\mathrm{C} \beta-\mathrm{H} \beta \beta)(9)+\phi(\mathrm{C} \gamma-\mathrm{C} \beta-\mathrm{H} \beta \alpha)(9)+ \\
v\left(\mathrm{C} \delta-\mathrm{O} \delta_{2}\right)(5)+v\left(\mathrm{C} \delta=\mathrm{O} \delta_{1}\right)(5)+\phi(\mathrm{C} \alpha-\mathrm{C} \beta-\mathrm{H} \beta \alpha)(5)\end{array}$ & 798 & 810 & - & $\begin{array}{l}v(\mathrm{C} \gamma-\mathrm{C} \delta)(17)+\omega(\mathrm{C}=\mathrm{O})(12)+v(\mathrm{C} \alpha-\mathrm{C} \beta)(8)+\omega(\mathrm{N}-\mathrm{H})(5)+ \\
\phi(\mathrm{O}=\mathrm{C}=\mathrm{N})(6)+\phi(\mathrm{C} \gamma-\mathrm{C} \beta-\mathrm{H} \beta \alpha)(5)+\phi(\mathrm{C} \gamma-\mathrm{C} \beta-\mathrm{H} \beta \beta)(5)\end{array}$ \\
\hline 763 & 768 & - & $\omega(\mathbf{C}=\mathrm{O})(49)+\omega(\mathrm{N}-\mathrm{H})(17)+v(\mathrm{C} \alpha-\mathrm{C} \beta)(6)$ & 778 & 768 & - & $\omega(\mathrm{C}=\mathrm{O})(32)+\omega(\mathrm{N}-\mathrm{H})(12)+v(\mathrm{C} \gamma-\mathrm{C} \delta)(11)+\phi(\mathrm{C} \gamma-\mathrm{C} \beta-\mathrm{H} \beta \alpha)(5)$ \\
\hline
\end{tabular}


$661 \quad 670-\omega(\mathrm{N}-\mathrm{H})(18)+\phi(\mathrm{N}-\mathrm{C} \alpha-\mathrm{C})(11)+\tau(\mathrm{C}=\mathrm{N})(9)+\omega(\mathrm{C}=\mathrm{O})(8)$

$\phi(\mathrm{C} \alpha-\mathrm{C}=\mathrm{N})(5) \quad$ (Amide $\mathrm{VI})$

$\begin{array}{llll}626 & - & - & \omega\left(\mathrm{C} \delta=\mathrm{O} \delta_{1}\right)(46)+\omega(\mathrm{N}-\mathrm{H})(9)+\phi(\mathrm{C} \beta-\mathrm{C} \gamma-\mathrm{C} \delta)(7)+\tau(\mathrm{C}=\mathrm{N})(5) \\ 554 & 567 & 582 & \omega(\mathrm{N}-\mathrm{H})(20)+\tau(\mathrm{C}=\mathrm{N})(18)+\phi(\mathrm{C} \alpha-\mathrm{C}=\mathrm{N})(8)+v(\mathrm{C} \alpha-\mathrm{C})(6)\end{array}$

(Amide $\mathrm{V}$ )

$505-\quad-\phi(\mathrm{C} \alpha-\mathrm{C}=\mathrm{O})(23)+v(\mathrm{C} \alpha-\mathrm{C})(14)+\phi\left(\mathrm{C} \gamma-\mathrm{C} \delta-\mathrm{O} \delta_{2}\right)(10)+$

$\phi(\mathrm{N}-\mathrm{C} \alpha-\mathrm{C} \beta)(10)+v(\mathrm{~N}-\mathrm{C} \alpha)(8)+v(\mathrm{C} \alpha-\mathrm{C} \beta)(7)+$

$\phi(\mathrm{C} \alpha-\mathrm{C}=\mathrm{N})(6)+\phi(\mathrm{O}=\mathrm{C}=\mathrm{N})(5)$

$471 \quad-\quad-\quad \phi\left(\mathrm{C} \gamma-\mathrm{C} \delta-\mathrm{O} \delta_{2}\right)(48)+\phi\left(\mathrm{O} \delta_{2}-\mathrm{C} \delta=\mathrm{O} \delta_{1}\right)(26)$

$408 \quad 409$

- $\phi(\mathrm{C} \alpha-\mathrm{C} \beta-\mathrm{C} \gamma)(30)+\phi(\mathrm{C}-\mathrm{C} \alpha-\mathrm{C} \beta)(14)+\phi\left(\mathrm{C} \gamma \mathrm{C} \delta=\mathrm{O} \delta_{1}\right)(6)$

$280 \phi(\mathrm{C}=\mathrm{N}-\mathrm{C} \alpha)(17)+\phi(\mathrm{O}=\mathrm{C}=\mathrm{N})(16)+\phi(\mathrm{N}-\mathrm{C} \alpha-\mathrm{C} \beta)(15)+$ $\phi(\mathrm{C} \alpha-\mathrm{C}=\mathrm{O})(13)+\phi(\mathrm{C} \beta-\mathrm{C} \gamma-\mathrm{C} \delta)(7)$ $\phi(\mathrm{C} \alpha-\mathrm{C}=\mathrm{O})(13)+\phi(\mathrm{C} \beta-\mathrm{C} \gamma-\mathrm{C} \delta)(7)$
u.c. $\alpha-\mathrm{C}=\mathrm{O})(13)+\phi(\mathrm{C} \beta-\mathrm{C} \gamma-\mathrm{C} \delta)(7)$

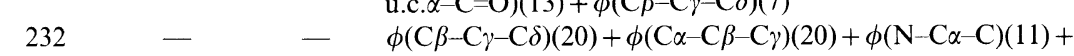

$\phi(\mathrm{C}-\mathrm{C} \alpha-\mathrm{C} \beta)(7)+\tau(\mathrm{C} \beta-\mathrm{C} \gamma)(5)+\tau(\mathrm{N}-\mathrm{C} \alpha)(5)$

$203-$

$\phi(\mathrm{N}-\mathrm{C} \alpha-\mathrm{C})(21)+\phi(\mathrm{C} \beta-\mathrm{C} \gamma-\mathrm{C} \delta)(18)+\phi(\mathrm{C}-\mathrm{C} \alpha-\mathrm{C} \beta)(12)+$

$\phi(\mathrm{C} \alpha-\mathrm{C}=\mathrm{N})(7)+\tau(\mathrm{C}-\mathrm{C} \alpha)(6)+\tau(\mathrm{C}=\mathrm{N})(6)+\phi(\mathrm{C} \alpha-\mathrm{C}=\mathrm{O})(6)+$

$141 \quad-\quad \begin{aligned} & \phi(\mathrm{C}-\mathrm{C} \alpha-\mathrm{C} \beta)(26)+\phi(\mathrm{C} \alpha-\mathrm{C}=\mathrm{N})(9)+\phi(\mathrm{O}=\mathrm{C}=\mathrm{N})(7)+ \\ & \tau(\mathrm{C} \beta-\mathrm{C} \gamma)(7)+\phi(\mathrm{N}-\mathrm{C} \alpha-\mathrm{C} \beta)(7)+\tau\left(\mathrm{C} \delta-\mathrm{O} \delta_{2}\right)(8)+\end{aligned}$ (Amide VII)

$\phi(\mathrm{C} \beta-\mathrm{C} \gamma-\mathrm{C} \delta)(5)$

$87-\quad-\quad \phi(\mathrm{N}-\mathrm{C} \alpha-\mathrm{C} \beta)(23)+\phi(\mathrm{C}=\mathrm{N}-\mathrm{C} \alpha)(14)+\phi(\mathrm{C} \alpha-\mathrm{C}=\mathrm{N})(11)+$

$\tau(\mathrm{C} \gamma-\mathrm{C} \delta)(10)+\tau(\mathrm{N}-\mathrm{C} \alpha)(7)+\tau(\mathrm{C}-\mathrm{C} \alpha)(6)+\phi(\mathrm{O}=\mathrm{C}=\mathrm{N})(5)$

$\phi(\mathrm{C}=\mathrm{N}-\mathrm{C} \alpha)(8)+\omega(\mathrm{C}=\mathrm{O})(7)$

$41-\quad-\tau(\mathrm{C} \gamma-\mathrm{C} \delta)(75)+\phi(\mathrm{N}-\mathrm{C} \alpha-\mathrm{C} \beta)(7)+\phi(\mathrm{C} \alpha-\mathrm{C} \beta-\mathrm{C} \gamma)(6)$

$24-\quad-\tau(\mathrm{C} \beta-\mathrm{C} \gamma)(69)+\tau(\mathrm{C} \alpha-\mathrm{C} \beta)(9)+\phi(\mathrm{C}-\mathrm{C} \alpha-\mathrm{C} \beta)(5)$

$15-\quad-\quad \tau(\mathrm{C} \alpha-\mathrm{C} \beta)(78)+\tau(\mathrm{C} \beta-\mathrm{C} \gamma)(11)$

\section{3}

615

591

502

452
$-\omega\left(\mathrm{C} \delta=\mathrm{O} \delta_{1}\right)(47)+\phi(\mathrm{C} \beta-\mathrm{C} \gamma-\mathrm{C} \delta)(10)+\phi\left(\mathrm{C} \gamma-\mathrm{C} \delta=\mathrm{O} \delta_{1}\right)(6)$

- $\omega(\mathrm{N}-\mathrm{H})(43)+\tau(\mathrm{C}=\mathrm{N})(26)+\omega(\mathrm{C}=\mathrm{O})(13) \quad$ (Amide $\mathrm{V}$ $v(\mathrm{C} \alpha-\mathrm{C})(20)+\phi(\mathrm{O}=\mathrm{C}=\mathrm{N})(15)+\phi(\mathrm{C}=\mathrm{N}-\mathrm{C} \alpha)(8)+\phi(\mathrm{C} \alpha-\mathrm{C}=\mathrm{N})(7)+$ $\omega(\mathrm{C}=\mathrm{O})(6)+\omega\left(\mathrm{C} \delta=\mathrm{O} \delta_{1}\right)(5)$ (Amide IV)

- $\phi\left(\mathrm{C} \gamma-\mathrm{C} \delta=\mathrm{O} \delta_{1}\right)(39)+\omega\left(\mathrm{C} \delta=\mathrm{O} \delta_{1}\right)(16)+\phi\left(\mathrm{C} \gamma-\mathrm{C} \delta-\mathrm{O} \delta_{2}\right)(7)+$ $\phi\left(\mathrm{O} \delta_{2}-\mathrm{C} \delta=\mathrm{O} \delta_{1}\right)(6)+\phi(\mathrm{C} \beta-\mathrm{C} \gamma-\mathrm{C} \delta)(5)$

$-\phi(\mathrm{C} \alpha-\mathrm{C}=\mathrm{O})(21)+\phi(\mathrm{C} \alpha \mathrm{C}=\mathrm{N})(9)+v(\mathrm{C} \alpha-\mathrm{C})(7)+$ $\phi(\mathrm{C}-\mathrm{C} \alpha-\mathrm{C} \beta)(6)+\phi(\mathrm{N}-\mathrm{C} \alpha-\mathrm{C} \beta)(6)$

$-\phi(\mathrm{C} \alpha-\mathrm{C} \beta-\mathrm{C} \gamma)(24)+\phi\left(\mathrm{C} \gamma \mathrm{C} \delta=\mathrm{O} \delta_{1}\right)(7)+\phi(\mathrm{C}-\mathrm{C} \alpha-\mathrm{C} \beta)(7)+$ $\phi(\mathrm{N}-\mathrm{C} \alpha-\mathrm{C})(7)+\phi(\mathrm{O}=\mathrm{C}=\mathrm{N})(5)$

$280 \phi(\mathrm{N}-\mathrm{C} \alpha-\mathrm{C} \beta)(18)+\phi(\mathrm{C}=\mathrm{N}-\mathrm{C} \alpha)(14)+\phi(\mathrm{O}=\mathrm{C}=\mathrm{N})(11)+$ $\phi(\mathrm{C} \beta-\mathrm{C} \gamma-\mathrm{C} \delta)(9)+\phi(\mathrm{C} \alpha-\mathrm{C}=\mathrm{O})(9)+\phi(\mathrm{N}-\mathrm{C}$

$-\phi(\mathrm{C} \beta-\mathrm{C} \gamma-\mathrm{C} \delta)(29)+\phi(\mathrm{N}-\mathrm{C} \alpha-\mathrm{C} \beta)(12)+\phi(\mathrm{C} \alpha-\mathrm{C}=\mathrm{N})(7)+$ $\phi(\mathrm{N}-\mathrm{C} \alpha-\mathrm{C})(8)+\phi(\mathrm{C} \alpha-\mathrm{C}=\mathrm{O})(5)$

$\phi(\mathrm{C} \alpha-\mathrm{C} \beta-\mathrm{C} \gamma)(20)+\phi(\mathrm{C}-\mathrm{C} \alpha-\mathrm{C} \beta)(13)+\phi(\mathrm{N}-\mathrm{C} \alpha-\mathrm{C})(11)+$ $\phi(\mathrm{C} \alpha-\mathrm{C}=\mathrm{N})(6)+\phi(\mathrm{N}-\mathrm{C} \alpha-\mathrm{C} \beta)(6)+\tau(\mathrm{N}-\mathrm{C} \alpha)(5)+\tau(\mathrm{C} \beta-\mathrm{C} \gamma)(5)+$ $\tau(\mathrm{C}-\mathrm{C} \alpha)(4)+\tau(\mathrm{C}=\mathrm{N})(4)+\phi(\mathrm{C} \alpha-\mathrm{C}=\mathrm{O})(4) \quad$ (Amide VII)

- $\phi(\mathrm{C}=\mathrm{N}-\mathrm{C} \alpha)(17)+\phi(\mathrm{C}-\mathrm{C} \alpha-\mathrm{C} \beta)(12)+\phi(\mathrm{N}-\mathrm{C} \alpha-\mathrm{C})(11)+$ $\phi(\mathrm{N}-\mathrm{C} \alpha-\mathrm{C} \beta)(10)+\tau(\mathrm{N}-\mathrm{C} \alpha)(9)+\phi(\mathrm{C} \beta-\mathrm{C} \gamma-\mathrm{C} \delta)(7)$

$-\tau(\mathrm{C}-\mathrm{C} \alpha)(16)+\phi(\mathrm{C}-\mathrm{C} \alpha-\mathrm{C} \beta)(14)+\phi(\mathrm{N}-\mathrm{C} \alpha-\mathrm{C} \beta)(9)+$ $\phi(\mathrm{C} \alpha-\mathrm{C}=\mathrm{N})(8)+\tau(\mathrm{N}-\mathrm{C} \alpha)(8)+\omega(\mathrm{C}=\mathrm{O})(7)+\phi(\mathrm{C}=\mathrm{N}-\mathrm{C} \alpha)(6)$

$-\tau(\mathrm{C}-\mathrm{C} \alpha)(22)+\tau(\mathrm{N}-\mathrm{C} \alpha)(11)+\phi(\mathrm{N}-\mathrm{C} \alpha-\mathrm{C})(10)+\tau(\mathrm{C} \beta-\mathrm{C} \gamma)(9)+$ $\phi(\mathrm{C} \alpha-\mathrm{C}=\mathrm{N})(7)+\tau(\mathrm{C}=\mathrm{N})(4)+$

$\tau(\mathrm{C} \gamma-\mathrm{C} \delta)(76)+\phi(\mathrm{C} \alpha-\mathrm{C} \beta-\mathrm{C} \gamma)(5)$

$\tau(\mathrm{C} \beta-\mathrm{C} \gamma)(61)+\tau(\mathrm{N}-\mathrm{C} \alpha)(11)$

$-\quad \tau(\mathrm{C} \alpha-\mathrm{C} \beta)(41)+\tau(\mathrm{C}-\mathrm{C} \alpha)(23)+\tau(\mathrm{N}-\mathrm{C} \alpha)(9)+\tau(\mathrm{C} \beta-\mathrm{C} \gamma)(6)+$ $\phi(\mathrm{N}-\mathrm{C} \alpha-\mathrm{C})(5)+\phi(\mathrm{C}-\mathrm{C} \alpha-\mathrm{C} \beta)(5)$

${ }^{a}$ Note: All frequencies are in $\mathrm{cm}^{-1}$. 
Table V. Comparison of amide modes of $\alpha$ PLG with other $\alpha$ helical polypeptides ${ }^{\mathrm{a}}$

\begin{tabular}{|c|c|c|c|c|c|c|c|c|}
\hline \multirow{2}{*}{ Modes } & \multicolumn{2}{|c|}{$\alpha$ PLG } & \multicolumn{2}{|c|}{$\alpha$ PLV } & \multicolumn{2}{|c|}{$\alpha$ PLA } & \multicolumn{2}{|c|}{$\alpha$ PLL } \\
\hline & $\delta=0.0$ & $\delta=5 \pi / 9$ & $\delta=0.0$ & $\delta=5 \pi / 9$ & $\delta=0.0$ & $\delta=5 \pi / 9$ & $\delta=0.0$ & $\delta=5 \pi / 9$ \\
\hline Amide A & 3301 & 3301 & 3293 & 3293 & 3293 & 3293 & 3313 & 3313 \\
\hline Amide I & 1652 & 1655 & 1655 & 1650 & 1659 & 1659 & 1657 & 1657 \\
\hline Amide II & 1510 & 1550 & 1535 & 1520 & 1515 & 1540 & 1546 & 1578 \\
\hline Amide III & 1283 & 1283 & 1246 & 1253 & 1270 & 1274 & 1299 & 1318 \\
\hline Amide IV & - & $591^{*}$ & 578 & 550 & 525 & 440 & 587 & 633 \\
\hline Amide V & 552 & 618 & 622 & 612 & 595 & 610 & 587 & 617 \\
\hline Amide VI & 670 & - & 691 & 691 & 685 & 656 & 656 & 533 \\
\hline Amide VII & 204 & 204 & 125 & 130 & 238 & 190 & 216 & - \\
\hline
\end{tabular}

a Notes: 1. All frequencies are given in $\mathrm{cm}^{-1} .2{ }^{*}$ marked frequencies are the calculated ones. $3 . \mathrm{PLG}=$ poly(L-glutamic acid); $\mathrm{PLV}=$ poly $(\mathrm{L}-\mathrm{valine}) ; \mathrm{PLA}=$ poly(L-alanine $) ; \mathrm{PLL}=$ poly $(\mathrm{L}-\mathrm{leucine})$.

Table VI. Frequency shifts on $N$-deuteration

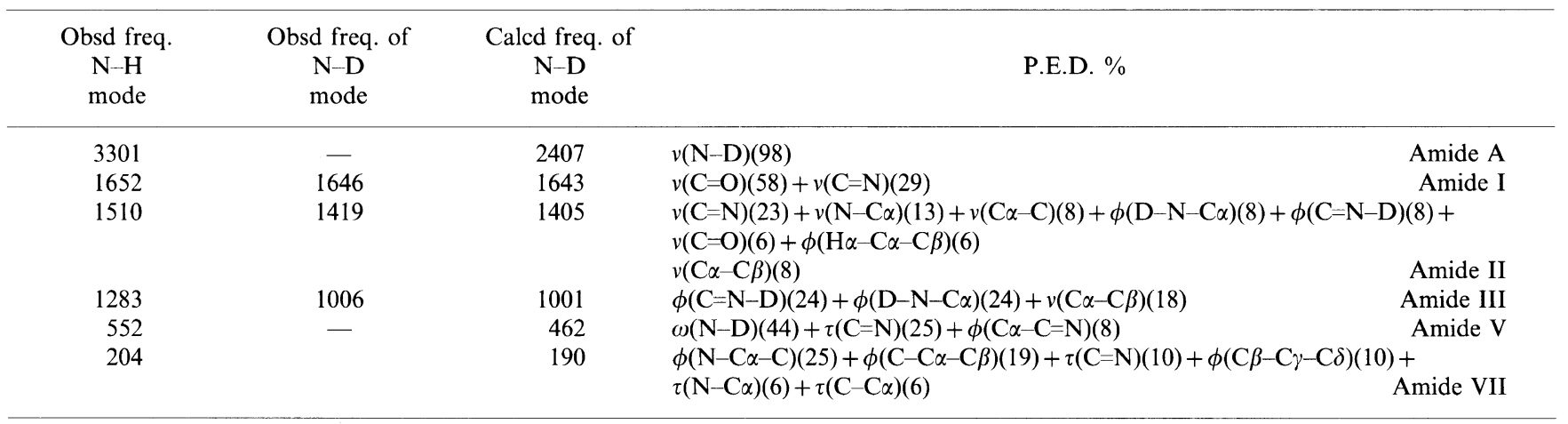

${ }^{a}$ Note: All frequencies are in $\mathrm{cm}^{-1}$.

Table VII. Pair of modes that repel and exchange character ${ }^{\mathbf{a}}$

\begin{tabular}{|c|c|c|c|c|c|c|c|c|c|}
\hline \multirow{2}{*}{$\begin{array}{l}\text { Freq. } \\
(\delta=0)\end{array}$} & \multicolumn{3}{|r|}{ Before exchange } & \multicolumn{6}{|c|}{ After exchange } \\
\hline & $\delta^{\alpha} / \pi$ & Freq. & P.E.D. & $\delta^{\beta} / \pi$ & Freq. & P.E.D. & $\delta^{\beta} / \pi$ & Freq. & P.E.D. \\
\hline 661 & 0.25 & 649 & $\begin{array}{l}\omega(\mathrm{N}-\mathrm{H})(16)+\omega(\mathrm{C}=\mathrm{O})(9)+ \\
\tau(\mathrm{C}=\mathrm{N})(9)+\omega\left(\mathrm{C} \delta=\mathrm{O} \delta_{1}\right)(12)+ \\
\phi(\mathrm{N}-\mathrm{C} \alpha-\mathrm{C})(8)+\phi(\mathrm{C} \beta-\mathrm{C} \gamma-\mathrm{C} \delta)(5)\end{array}$ & 0.56 & 633 & $\begin{array}{l}\omega\left(\mathrm{C} \delta=\mathrm{O} \delta_{1}\right)(47)+ \\
\phi(\mathrm{C} \beta-\mathrm{C} \gamma-\mathrm{C} \delta)(10)+ \\
\phi\left(\mathrm{C} \gamma-\mathrm{C} \delta=\mathrm{O} \delta_{1}\right)(6)\end{array}$ & 0.80 & 634 & $\begin{array}{l}\omega(\mathrm{N}-\mathrm{H})(16)+\omega\left(\mathrm{C} \delta=\mathrm{O} \delta_{1}\right)(18)+ \\
\tau(\mathrm{C}=\mathrm{N})(12)\end{array}$ \\
\hline 626 & & 624 & $\begin{array}{l}\omega\left(\mathrm{C} \delta=\mathrm{O} \delta_{1}\right)(39)+\omega(\mathrm{N}-\mathrm{H})(13)+ \\
\phi(\mathrm{C} \beta-\mathrm{C} \gamma-\mathrm{C} \delta)(5)+\tau(\mathrm{C}=\mathrm{N})(6)\end{array}$ & & 615 & $\begin{array}{l}\omega(\mathrm{N}-\mathrm{H})(43)+ \\
\omega(\mathrm{C}=\mathrm{O})(13)+ \\
\tau(\mathrm{C}=\mathrm{N})(26)\end{array}$ & & 631 & $\begin{array}{l}\omega\left(\mathrm{C} \delta=\mathrm{O} \delta_{1}\right)(34)+\omega(\mathrm{N}-\mathrm{H})(9)+ \\
\phi(\mathrm{C} \beta-\mathrm{C} \gamma-\mathrm{C} \delta)(6)\end{array}$ \\
\hline 554 & & 567 & $\begin{array}{l}\omega(\mathrm{N}-\mathrm{H})(18)+\tau(\mathrm{C}=\mathrm{N})(14)+ \\
\phi(\mathrm{C} \alpha-\mathrm{C}=\mathrm{N})(8)+v(\mathrm{C}-\mathrm{C} \alpha)(10)+ \\
\phi(\mathrm{O}=\mathrm{C}=\mathrm{N})(8)\end{array}$ & & 591 & $\begin{array}{l}\phi(\mathrm{O}=\mathrm{C}=\mathrm{N})(15)+ \\
\phi(\mathrm{C} \alpha-\mathrm{C}=\mathrm{N})(7)+ \\
v(\mathrm{C}-\mathrm{C} \alpha)(20)+ \\
\omega\left(\mathrm{C} \delta=\mathrm{O} \delta_{1}\right)(5)+ \\
\omega(\mathrm{C}=\mathrm{O})(6)\end{array}$ & & 577 & $\begin{array}{l}v(\mathrm{C}-\mathrm{C} \alpha)(17)+\phi(\mathrm{O}=\mathrm{C}=\mathrm{N})(14)+ \\
\phi(\mathrm{C}=\mathrm{N}-\mathrm{C} \alpha)(5)+\omega(\mathrm{C}=\mathrm{O})(6) \\
\tau(\mathrm{C}=\mathrm{N})(16)+\omega(\mathrm{N}-\mathrm{H})(15)\end{array}$ \\
\hline 504 & 0.00 & 504 & $\begin{array}{l}\phi(\mathrm{C} \alpha-\mathrm{C}=\mathrm{O})(23)+v(\mathrm{C} \alpha-\mathrm{C})(14)+ \\
\phi(\mathrm{N}-\mathrm{C} \alpha-\mathrm{C} \beta)(10)+v(\mathrm{~N}-\mathrm{C} \alpha)(8)+ \\
\phi(\mathrm{O}=\mathrm{C}=\mathrm{N})(5)+\phi(\mathrm{C} \alpha-\mathrm{C}=\mathrm{N})(6)+ \\
\phi\left(\mathrm{C} \gamma-\mathrm{C} \delta-\mathrm{O} \delta_{2}\right)(10)+v(\mathrm{C} \alpha-\mathrm{C} \beta)(7)\end{array}$ & 0.15 & 503 & $\begin{array}{l}\phi\left(\mathrm{C} \gamma-\mathrm{C} \delta=\mathrm{O} \delta_{1}\right)(20)+ \\
\phi(\mathrm{C} \alpha-\mathrm{C}=\mathrm{O})(12)+ \\
\omega\left(\mathrm{C} \delta=\mathrm{O} \delta_{1}\right)(10)+ \\
\phi\left(\mathrm{C} \gamma-\mathrm{C} \delta-\mathrm{O} \delta_{2}\right)(9)+ \\
\phi(\mathrm{N}-\mathrm{C} \alpha-\mathrm{C} \beta)(6)+ \\
v(\mathrm{C}-\mathrm{C} \alpha)(7)\end{array}$ & 0.40 & 502 & $\begin{array}{l}\phi\left(\mathrm{C} \gamma-\mathrm{C} \delta=\mathrm{O} \delta_{1}\right)(37)+\omega\left(\mathrm{C} \delta=\mathrm{O} \delta_{1}\right)(17)+ \\
\phi\left(\mathrm{C} \gamma-\mathrm{C} \delta-\mathrm{O} \delta_{2}\right)(9)+ \\
\phi\left(\mathrm{O} \delta_{2}-\mathrm{C} \delta=\mathrm{O} \delta_{1}\right)(8)\end{array}$ \\
\hline 498 & & & $\begin{array}{l}\phi\left(\mathrm{C} \gamma-\mathrm{C} \delta=\mathrm{O} \delta_{1}\right)(41)+ \\
\omega\left(\mathrm{C} \delta=\mathrm{O} \delta_{1}\right)(14)+ \\
\phi\left(\mathrm{O} \delta_{2}-\mathrm{C} \delta=\mathrm{O} \delta_{1}\right)(9)\end{array}$ & & 494 & $\begin{array}{l}\phi\left(\mathrm{C} \gamma-\mathrm{C} \delta=\mathrm{O} \delta_{1}\right)(23)+ \\
\phi(\mathrm{C} \alpha-\mathrm{C}=\mathrm{O})(11)+ \\
\phi\left(\mathrm{O} \delta_{2}-\mathrm{C} \delta=\mathrm{O} \delta_{1}\right)(8) \\
\phi\left(\mathrm{C} \gamma-\mathrm{C} \delta-\mathrm{O} \delta_{2}\right)(6)+ \\
\omega\left(\mathrm{C} \delta=\mathrm{O} \delta_{1}\right)(6)+ \\
\phi(\mathrm{C} \alpha-\mathrm{C}=\mathrm{N})(5)\end{array}$ & & 478 & $\begin{array}{l}\phi\left(\mathrm{C} \gamma-\mathrm{C} \delta-\mathrm{O} \delta_{2}\right)(38)+ \\
\phi\left(\mathrm{O} \delta_{2}-\mathrm{C} \delta=\mathrm{O} \delta_{1}\right)(22)\end{array}$ \\
\hline 471 & & & $\begin{array}{l}\phi\left(\mathrm{C} \gamma-\mathrm{C} \delta-\mathrm{O} \delta_{2}\right)(48)+ \\
\phi\left(\mathrm{O} \delta_{2}-\mathrm{C} \delta=\mathrm{O} \delta_{1}\right)(26)\end{array}$ & & 471 & $\begin{array}{l}\phi\left(\mathrm{C} \gamma-\mathrm{C} \delta-\mathrm{O} \delta_{2}\right)(48)+ \\
\phi\left(\mathrm{O} \delta_{2}-\mathrm{C} \delta=\mathrm{O} \delta_{1}\right)(25) \\
\phi(\mathrm{C} \alpha-\mathrm{C}=\mathrm{O})(6)\end{array}$ & & 464 & $\begin{array}{l}\phi(\mathrm{C} \alpha-\mathrm{C}=\mathrm{O})(19)+\phi\left(\mathrm{C} \gamma-\mathrm{C} \delta-\mathrm{O} \delta_{2}\right)(15)+ \\
v(\mathrm{C} \alpha-\mathrm{C})(8)+\phi(\mathrm{C} \alpha-\mathrm{C}=\mathrm{N})(8)+ \\
\phi\left(\mathrm{O} \delta_{2}-\mathrm{C} \delta=\mathrm{O} \delta_{1}\right)(18)\end{array}$ \\
\hline
\end{tabular}

${ }^{a}$ Notes: 1) $\alpha$ marked $\delta$ corresponds to the points before exchange. 2) $\beta$ marked $\delta$ corresponds to the points after exchange. 
frequency in IR or in Raman. The next observed frequency at $1388 \mathrm{~cm}^{-1}$ is a mixture of $\mathrm{H} \alpha$ bend with $\mathrm{C}_{\beta} \mathrm{H}_{2}$ wag and it is calculated at $1396 \mathrm{~cm}^{-1}$. The modes calculated at $1052 \mathrm{~cm}^{-1}$ and $1039 \mathrm{~cm}^{-1}$ are $(\mathrm{C} \alpha-\mathrm{C} \beta)$ and $(\mathrm{C} \beta-\mathrm{C} \gamma)$ stretching modes. Observed values of these modes in the IR and Raman spectra are 1060, 1057, 1028, and $1030 \mathrm{~cm}^{-1}$, respectively. Both of these modes are nondispersive. Although both of these modes arise due to $v(\mathrm{C}-\mathrm{C})$ yet they appear about $32 \mathrm{~cm}^{-1}$ apart. This is due to the proximity of $(\mathrm{C} \alpha-\mathrm{C} \beta)$ to amide group and greater interaction with it. As one moves away from it, the interaction decreases and the following inequality holds $v(\mathrm{C} \alpha-\mathrm{C} \beta)>v(\mathrm{C} \beta-\mathrm{C} \gamma)>v(\mathrm{C} \gamma-\mathrm{C} \delta)$. The mixture of $(\mathrm{C} \gamma-\mathrm{C} \delta)$ stretch and $\mathrm{CH}_{2}$ rocking is calculated at 800 $\mathrm{cm}^{-1}$ and has been assigned to the observed peak at $810 \mathrm{~cm}^{-1}$. The assignments of $\mathrm{C}_{\beta} \mathrm{H}_{2}$ rocking, scissoring, and wagging modes are consistent with those in $\alpha$-PLL and $\alpha$-PBLG. ${ }^{31}$ These modes are localised and not very sensitive to the side chain conformation.

\section{CHARACTERISTIC FEATURES OF DISPERSION CURVES}

One of the interesting feature of the dispersion curves is the tendency of some curves to come closer and exchange their character. Firstly the exchange of potential energy is observed between the modes calculated at 661,626 , and $554 \mathrm{~cm}^{-1}$. At $\delta=0661 \mathrm{~cm}^{-1}$ mode is a mixture of $\omega(\mathrm{N}-\mathrm{H}), \tau(\mathrm{C} \cdots \mathrm{N}), \omega(\mathrm{C} \cdots \mathrm{O})$, $\phi(\mathrm{N}-\mathrm{C} \alpha-\mathrm{C})$, and $\phi(\mathrm{C} \alpha-\mathrm{C}-\mathrm{N})$ whereas the $626 \mathrm{~cm}^{-1}$ mode consists of predominantly $\omega\left(\mathrm{C} \delta=\mathrm{O} \delta_{1}\right)$ and small contributions from $\omega(\mathrm{N}-\mathrm{H})$ and $\tau(\mathrm{C} \cdots \mathrm{N})$. As stated earlier the $554 \mathrm{~cm}^{-1}$ mode is mainly $\omega(\mathrm{N}-\mathrm{H})$ and $\tau(\mathrm{C} \cdots \mathrm{N})$ mixed with $(\mathrm{C} \alpha-\mathrm{C} \cdots \mathrm{N})$ bending and $(\mathrm{C} \alpha-\mathrm{C})$ stretch. On increasing the value of $\delta,\left(\mathrm{C} \delta=\mathrm{O} \delta_{1}\right)$ wag starts appearing in the $661 \mathrm{~cm}^{-1}$ mode. The contribution of $\omega(\mathrm{N}-\mathrm{H})$ starts increasing in $626 \mathrm{~cm}^{-1}$ mode and $(\mathrm{O} \cdots \mathrm{C}$ $\cdots \mathrm{N}$ ) bending starts appearing in $554 \mathrm{~cm}^{-1}$ mode. At $\delta=5 \pi / 9$ the $661 \mathrm{~cm}^{-1}$ mode becomes mainly $\omega\left(\mathrm{C} \delta=\mathrm{O} \delta_{1}\right)$, the $626 \mathrm{~cm}^{-1}$ mode which was mainly $\omega\left(\mathrm{C} \delta=\mathrm{O} \delta_{1}\right)$ at $\delta=0$ becomes a mixture of $\omega(\mathrm{N}-\mathrm{H})$ and $\tau(\mathrm{C}-\mathrm{N})$, i.e., amide $\mathrm{V}$ and the mode which was amide $\mathrm{V}$ at $\delta=0$ becomes a mixed mode of $\phi(\mathrm{O} \cdots \mathrm{C} \cdots \mathrm{N}), \phi(\mathrm{C} \cdots \mathrm{N}-\mathrm{C} \alpha), v(\mathrm{C} \alpha-\mathrm{C})$, $\omega(\mathrm{C} \cdots \mathrm{O})$, and $\omega\left(\mathrm{C} \delta=\mathrm{O} \delta_{1}\right)$. On further increasing the $\delta$ value beyond $0.75 \pi$ again an exchange of potential energy is observed between the $661 \mathrm{~cm}^{-1}$ and $626 \mathrm{~cm}^{-1}$ modes. Finally at $\delta=\pi, 661 \mathrm{~cm}^{-1}$ is a mixture of $\omega(\mathrm{N}-\mathrm{H})$ and $\tau(\mathrm{C} \cdots \mathrm{N})$ and $626 \mathrm{~cm}^{-1}$ is mainly $\omega\left(\mathrm{C} \delta=\mathrm{O} \delta_{1}\right)$.

Similar exchange of energy is again observed amongst the modes calculated at 504,498 , and $471 \mathrm{~cm}^{-1}$. At $\delta=0$, $504 \mathrm{~cm}^{-1}$ mode is a mixture of several skeletal deformations, stretches and $\phi\left(\mathrm{C} \gamma-\mathrm{C} \delta-\mathrm{O} \delta_{2}\right) .498 \mathrm{~cm}^{-1}$ consists of $\phi\left(\mathrm{C} \gamma-\mathrm{C} \delta=\mathrm{O} \delta_{1}\right)$ and $\phi\left(\mathrm{O} \delta_{2}-\mathrm{C} \delta=\mathrm{O} \delta_{1}\right)$ and 471 $\mathrm{cm}^{-1}$ is a mixture of $\phi\left(\mathrm{C} \gamma-\mathrm{C} \delta-\mathrm{O} \delta_{1}\right), \omega\left(\mathrm{C} \delta=\mathrm{O} \delta_{1}\right)$, and $\phi\left(\mathrm{O} \delta_{2}-\mathrm{C} \delta=\mathrm{O} \delta_{1}\right)$. With the increase in $\delta$ value contribution of $\phi\left(\mathrm{C} \gamma-\mathrm{C} \delta=\mathrm{O} \delta_{1}\right)$ starts increasing in the 504 $\mathrm{cm}^{-1}$ mode and the contribution of $\phi\left(\mathrm{C} \gamma-\mathrm{C} \delta-\mathrm{O} \delta_{2}\right)$ increases in the $498 \mathrm{~cm}^{-1}$ mode. At $\delta=\pi$ the $471 \mathrm{~cm}^{-1}$ mode becomes a mixture of skeletal deformations, and the $498 \mathrm{~cm}^{-1}$ becomes a mixture of $\phi\left(\mathrm{C} \gamma-\mathrm{C} \delta-\mathrm{O} \delta_{2}\right)$ and $\phi\left(\mathrm{O} \delta_{2}-\mathrm{C} \delta=\mathrm{O} \delta_{1}\right)$. Similarly $504 \mathrm{~cm}^{-1}$ becomes a mixture of $\phi\left(\mathrm{C} \gamma-\mathrm{C} \delta=\mathrm{O} \delta_{1}\right)+\omega\left(\mathrm{C} \delta=\mathrm{O} \delta_{1}\right)+\phi\left(\mathrm{C} \gamma-\mathrm{C} \delta-\mathrm{O} \delta_{2}\right)+$ $\phi\left(\mathrm{O} \delta_{2}-\mathrm{C} \delta=\mathrm{O} \delta_{1}\right)$.

All these modes wherein exchange of energy takes place are angle bends which belong to same symmetry species of the point group for the $\alpha$ helix. ${ }^{24}$

\section{INELASTIC NEUTRON SCATTERING SPECTRA}

The technique of inelastic neutron scattering (INS) ${ }^{13}$ which is very useful in studying the low frequency vibrations in polymers has been applied to confirm the assignment of low frequency modes. Because of the symmetry dependent selection rules, only a limited information regarding molecular dynamics can be obtained from infrared absorption and Raman scattering whereas neutron scattering being free from such constraints provides, at least in principle, full additional information about molecular systems. Also since the low

Table VIII. I.N.S. frequencies

\begin{tabular}{|c|c|c|c|c|c|}
\hline Calcd & $\begin{array}{l}\text { Obsd. } \\
\text { in } \\
\text { INS }\end{array}$ & Assignment ( $\%$ P.E.D. at $\delta=0.00$ ) & Calcd & $\begin{array}{l}\text { Obsd } \\
\text { in } \\
\text { INS }\end{array}$ & Assignment (\% P.E.D. at $\delta=0.56$ ) \\
\hline 554 & 552 & $\begin{array}{l}\omega(\mathrm{N}-\mathrm{H})(20)+\tau(\mathrm{C}=\mathrm{N})(18)+ \\
\phi(\mathrm{C} \alpha-\mathrm{C}=\mathrm{N})(8)+v(\mathrm{C} \alpha-\mathrm{C})(6)\end{array}$ & 591 & - & $\begin{array}{l}v(\mathrm{C} \alpha-\mathrm{C})(20)+\phi(\mathrm{O}=\mathrm{C}=\mathrm{N})(15)+\phi(\mathrm{C}=\mathrm{N}-\mathrm{C} \alpha)(8)+ \\
\phi(\mathrm{C} \alpha-\mathrm{C}=\mathrm{N})(7)+\omega(\mathrm{C}=\mathrm{O})(6)+\omega\left(\mathrm{C} \delta=\mathrm{O} \delta_{1}\right)(5)\end{array}$ \\
\hline 290 & 312 & $\begin{array}{l}\phi(\mathrm{C}=\mathrm{N}-\mathrm{C} \alpha)(17)+\phi(\mathrm{O}=\mathrm{C}=\mathrm{N})(16)+ \\
\phi(\mathrm{N}-\mathrm{C} \alpha-\mathrm{C} \beta)(15)+\phi(\mathrm{C} \alpha-\mathrm{C}=\mathrm{O})(13)+ \\
\phi(\mathrm{C} \beta-\mathrm{C} \gamma-\mathrm{C} \delta)(7)\end{array}$ & 298 & 312 & $\begin{array}{l}\phi(\mathrm{N}-\mathrm{C} \alpha-\mathrm{C} \beta)(18)+\phi(\mathrm{C}=\mathrm{N}-\mathrm{C} \alpha)(14)+ \\
\phi(\mathrm{O}=\mathrm{C}=\mathrm{N})(11)+\phi(\mathrm{C} \beta-\mathrm{C} \gamma-\mathrm{C} \delta)(9)+ \\
\phi(\mathrm{C} \alpha-\mathrm{C}=\mathrm{O})(9)+\phi(\mathrm{N}-\mathrm{C} \alpha-\mathrm{C})(7)\end{array}$ \\
\hline 232 & 228 & $\begin{array}{l}\phi(\mathrm{C} \beta-\mathrm{C} \gamma-\mathrm{C} \delta)(20)+\phi(\mathrm{C} \alpha-\mathrm{C} \beta-\mathrm{C} \gamma)(20)+ \\
\phi(\mathrm{N}-\mathrm{C} \alpha-\mathrm{C})(11)+\phi(\mathrm{C}-\mathrm{C} \alpha-\mathrm{C} \beta)(7)+ \\
\tau(\mathrm{C} \beta-\mathrm{C} \gamma)(5)+\tau(\mathrm{N}-\mathrm{C} \alpha)(5)\end{array}$ & 243 & 264 & $\begin{array}{l}\phi(\mathrm{C} \beta-\mathrm{C} \gamma-\mathrm{C} \delta)(29)+\phi(\mathrm{N}-\mathrm{C} \alpha-\mathrm{C} \beta)(12)+ \\
\phi(\mathrm{C} \alpha-\mathrm{C}=\mathrm{N})(7)+\phi(\mathrm{N}-\mathrm{C} \alpha-\mathrm{C})(6)+ \\
\phi(\mathrm{C} \alpha-\mathrm{C}=\mathrm{O})(5)\end{array}$ \\
\hline 169 & 176 & $\tau\left(\mathrm{C} \delta-\mathrm{O} \delta_{2}\right)(93)$ & 167 & 176 & $\tau\left(\mathrm{C} \delta-\mathrm{O} \delta_{2}\right)(97)$ \\
\hline 141 & 148 & $\begin{array}{l}\phi(\mathrm{C}-\mathrm{C} \alpha-\mathrm{C} \beta)(26)+\phi(\mathrm{C} \alpha-\mathrm{C}=\mathrm{N})(9)+ \\
\phi(\mathrm{O}=\mathrm{C}=\mathrm{N})(7)+\tau(\mathrm{C} \beta-\mathrm{C} \gamma)(7)+ \\
\phi(\mathrm{N}-\mathrm{C} \alpha-\mathrm{C} \beta)(7)+\tau\left(\mathrm{C} \delta-\mathrm{O} \delta_{2}\right)(6)+ \\
\phi(\mathrm{C} \beta-\mathrm{C} \gamma-\mathrm{C} \delta)(5)\end{array}$ & 121 & 128 & $\begin{array}{l}\phi(\mathrm{C}=\mathrm{N}-\mathrm{C} \alpha)(17)+\phi(\mathrm{C}-\mathrm{C} \alpha-\mathrm{C} \beta)(12)+ \\
\phi(\mathrm{N}-\mathrm{C} \alpha-\mathrm{C})(11)+\phi(\mathrm{N}-\mathrm{C} \alpha-\mathrm{C} \beta)(10)+ \\
\tau(\mathrm{N}-\mathrm{C} \alpha)(9)+\phi(\mathrm{C} \beta-\mathrm{C} \gamma-\mathrm{C} \delta)(7)\end{array}$ \\
\hline 87 & 92 & $\begin{array}{l}\phi(\mathrm{N}-\mathrm{C} \alpha-\mathrm{C} \beta)(23)+\phi(\mathrm{C}=\mathrm{N}-\mathrm{C} \alpha)(14)+ \\
\phi(\mathrm{C} \alpha-\mathrm{C}=\mathrm{N})(11)+\tau(\mathrm{C} \gamma-\mathrm{C} \delta)(10)+\tau(\mathrm{N}-\mathrm{C} \alpha)(7)+ \\
\tau(\mathrm{C}-\mathrm{C} \alpha)(6)+\phi(\mathrm{O}=\mathrm{C}=\mathrm{N})(5)\end{array}$ & 100 & 112 & $\begin{array}{l}\tau(\mathrm{C}-\mathrm{C} \alpha)(16)+\phi(\mathrm{C}-\mathrm{C} \alpha-\mathrm{C} \beta)(14)+ \\
\phi(\mathrm{N}-\mathrm{C} \alpha-\mathrm{C} \beta)(9)+\phi(\mathrm{C} \alpha-\mathrm{C}=\mathrm{N})(9)+ \\
\tau(\mathrm{N}-\mathrm{C} \alpha)(8)+\omega(\mathrm{C}=\mathrm{O})(7)+\phi(\mathrm{C}=\mathrm{N}-\mathrm{C} \alpha)(6)\end{array}$ \\
\hline 70 & 76 & $\begin{array}{l}\tau(\mathrm{C}-\mathrm{C} \alpha)(31)+\phi(\mathrm{N}-\mathrm{C} \alpha-\mathrm{C})(16)+\tau(\mathrm{N}-\mathrm{C} \alpha)(14)+ \\
\phi(\mathrm{C}=\mathrm{N}-\mathrm{C} \alpha)(8)+\omega(\mathrm{C}=\mathrm{O})(7)\end{array}$ & 64 & 60 & $\begin{array}{l}\tau(\mathrm{C}-\mathrm{C} \alpha)(22)+\tau(\mathrm{N}-\mathrm{C} \alpha)(11)+\phi(\mathrm{N}-\mathrm{C} \alpha-\mathrm{C})(10)+ \\
\tau(\mathrm{C} \beta-\mathrm{C} \gamma)(9)+\phi(\mathrm{C} \alpha-\mathrm{C}=\mathrm{N})(7)+\tau(\mathrm{C}=\mathrm{N})(4)\end{array}$ \\
\hline
\end{tabular}

${ }^{a}$ Notes: All frequencies are in $\mathrm{cm}^{-1}$. 
frequency vibrations are expected to depend sensitively on the chain conformation neutron spectra is expected to provide some of these conformation sensitive modes more prominently, especially those which involve large amplitude of proton motion.

Intensities in the neutron spectra are weighted by the vibrational amplitude of the motions of the hydrogen atoms. The peaks in the INS frequency distribution spectra can be identified with the regions of high density-of-states arising at the zone centre or within the zone (reduced zone scheme). Table VIII provides this identification. As stated earlier these modes involve motion of hydrogen atoms and hence appear intense. For example since $\mathrm{C} \alpha$ and $\mathrm{N}$ have a hydrogen attached to them the torsional motions about $(\mathrm{C}-\mathrm{C} \alpha),(\mathrm{N}-\mathrm{C} \alpha)$, and $(\mathrm{C} \cdots \mathrm{N})$ bond and bendings of $(\mathrm{C} \alpha-\mathrm{C}-\mathrm{O})$, $(\mathrm{N} \cdots \mathrm{C}-\mathrm{C} \alpha)$, and $(\mathrm{N}-\mathrm{C} \alpha-\mathrm{C} \beta)$ would necessarily involve large amplitude of hydrogen atoms. Similarly $\mathrm{O} \delta$ atom has a hydrogen attached to it, hence the torsional motion about $\left(\mathrm{C} \delta=\mathrm{O} \delta_{1}\right)$ would also involve large amplitude of hydrogen atom and will appear as a strong peak in the neutron spectra.

The mode calculated at $290 \mathrm{~cm}^{-1}$ is a mixed mode of $\phi(\mathrm{C}-\mathrm{N}-\mathrm{C} \alpha)(17)+\phi(\mathrm{O} \cdots \mathrm{C}-\mathrm{N})(16)+\phi(\mathrm{N}-\mathrm{C} \alpha-\mathrm{C} \beta)-$ $(15)+\phi(\mathrm{C} \alpha-\mathrm{C}-\mathrm{O})(13)$. The observed value of this mode is $280 \mathrm{~cm}^{-1}$ in Raman and $312 \mathrm{~cm}^{-1}$ in INS.

The amide $\mathrm{V}$ which mainly consist of $\omega(\mathrm{N}-\mathrm{H})$ and $\tau(\mathrm{C} \cdots \mathrm{N})$ is expected to be quite sensitive to the chain conformation and would involve large amplitude of hydrogen motions. This mode has been calculated at $554 \mathrm{~cm}^{-1}$ and it is observed as a very strong peak at $552 \mathrm{~cm}^{-1}$.

(C-O) torsion of $\mathrm{COOH}$ group is calculated at $168 \mathrm{~cm}^{-1}$, this band also appears very intense in the neutron spectra at $176 \mathrm{~cm}^{-1}$ due to the motion of $\mathrm{H} \delta$. Bending of $(\mathrm{C} \alpha-\mathrm{C} \beta-\mathrm{C} \gamma)$ and $(\mathrm{C} \beta-\mathrm{C} \gamma-\mathrm{C} \delta)$ has been calculated at $232 \mathrm{~cm}^{-1}$ and this corresponds to $228 \mathrm{~cm}^{-1}$ in the neutron spectra.

The $70 \mathrm{~cm}^{-1}$ mode which is a mixture of $(\mathrm{C}-\mathrm{C} \alpha)$, $(\mathrm{N}-\mathrm{C} \alpha)$ torsions and $(\mathrm{N}-\mathrm{C} \alpha-\mathrm{C})$ and $(\mathrm{C}-\mathrm{N}-\mathrm{C} \alpha)$ bendings has been identified with the observed peak at $76 \mathrm{~cm}^{-1}$ in the neutron spectra.

Some of the low frequency modes, e.g., 312 and 264 $\mathrm{cm}^{-1}$ are not in very good agreement with our calculated values. These modes may be arising due to interchain interactions in the lattice which have not been considered by us as our calculations are for an isolated chain.

\section{HEAT CAPACITY}

The dispersion curves thus obtained have been used for obtaining heat capacity as a function of temperature. The predictive values of heat capacity have been calculated in the temperature range $150-500 \mathrm{~K}$. Results are shown in Figure 6. Separate contributions are given from back bone (A), side chain (B), and mix modes (C). The contribution of the side chain is higher than that of the back bone because the number of atoms involved in the two types of modes are 10 and 6, respectively. However the maximum contribution comes from the coupled side chain and back bone modes because these modes involve the vibrations of all the atoms.

From a comparison of the heat capacity contribution

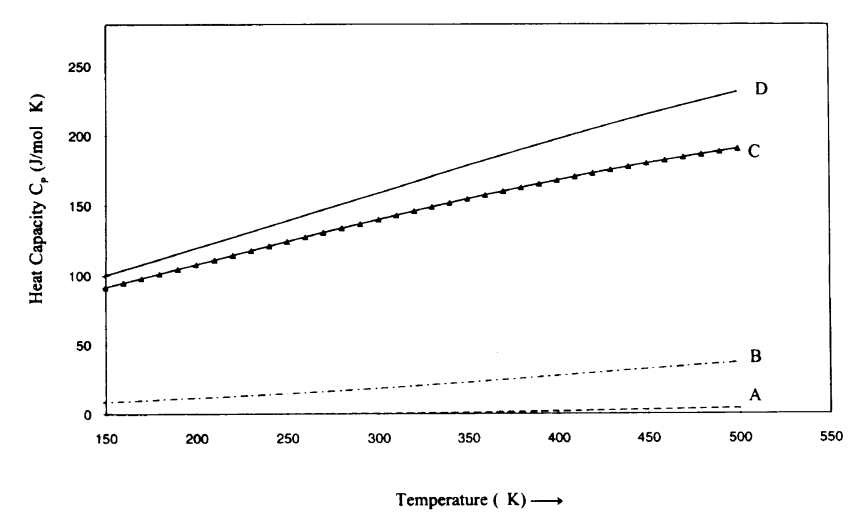

Figure 6a. Variation of heat capacity $C_{\mathrm{p}}$ of $\alpha$ PLG with temperature. (A) $(---)$ contribution of backbone modes; (B) $(-\cdot-)$ contribution of side chain modes; (C) (-) contribution of mix modes; (D) $(-)$ total heat capacity.

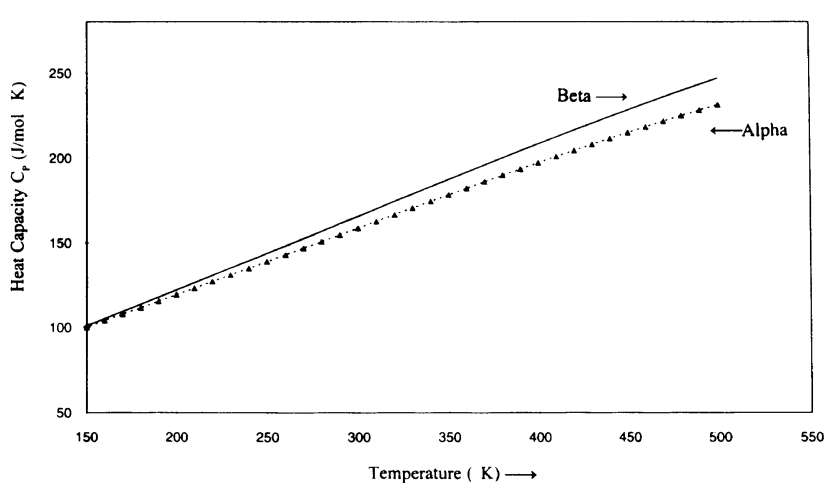

Figure 6b. Comparison of heat capacities of $\alpha$ and $\beta_{2}$ form.

due to side chain, back bone and mixed modes in two conformations $\alpha$ and $\beta_{2}$ it appears that the contribution of the back bone and mixed modes to the heat capacity is higher in case of $\beta_{2}$ form $^{32}$ and the contribution of the side chain mode is higher in $\alpha$ helical form. This result indicates a greater coupling of side chain and back bone modes in $\beta_{2}$ form than $\alpha$ helix. The total heat capacity of both the forms in the temperature range $150-500 \mathrm{~K}$ is shown in Figure 6b. The two heat capacities diverge beyond $150 \mathrm{~K}$, that for the $\beta_{2}$ form being higher than the $\alpha$ form. The relative magnitude of the heat capacity depends on the relative weightage of the low frequency modes in the two conformations to which heat capacity is sensitive.

The contribution from the lattice modes is bound to make an appreciable difference to the heat capacity because of its sensitivity to these modes. However in neutron scattering such contributions are not going to be very large because they mostly involve interchain translational and hindered rotational motions where in the hydrogens do not move with violence. At the moment, theoretically the calculation for dispersion curves for a unit cell are extremely difficult. Even if for simplicity we assume a minimum of two chains in unit cell then there would be 576 atoms leading to a matrix of $1728 \times 1728$. It would also bring in an enormous number of interactions which are difficult to visualize and two together make the problem somewhat intractable. However inspite-of several limitations involved in the calculation of specific heat, the present work does provide a good starting point for further basic studies on thermo- 
dynamical behavior of polypeptides and proteins which go into well-defined conformations.

Acknowledgments. Finacial assistance to V.D.G. and S.S. from Council of Scientific and Industrial Research, New Delhi under the Emeritus Scientist Scheme is gratefully acknowledged. The authors are also greatful to Dr. H. Prask at the NIST, Gaithesberg, Md. for the INS spectra.

\section{REFERENCES}

1. H. Lenormant, A. Baudras, and E. R. Blout, J. Am. Chem. Soc., 80, 6191 (1958)

2. M. L. Tiffany and S. Krimm, Biopolymers, 6, 1379 (1968).

3. H. D. Keith, F. J. Padden, and G. Giannoni, J. Mol. Biol., 43, 423 (1969).

4. H. D. Keith, G. Giannoni, and F. J. Padden, Biopolymers, 7, 775 (1969).

5. H. D. Keith, Biopolymers, 10, 1099 (1970).

6. J. L. Koenig and B. G. Frushour, Biopolymers, 11, 1871 (1972).

7. S. S. Zimmerman, J. C. Clark, and L. Mandelkern, Biopolymers, 14, 585 (1975).

8. K. Itoh, B. M. Foxman, and G. D. Fasman, Biopolymers, 15, 419 (1976).

9. G. D. Fasman, K. Itoh, C. S. Liu, and R. C. Lord, Biopolymers, 17, 1729 (1978).

10. H. Picova, V. Saudek, P. Schmidt, D. Hlavata, and J. Plestil, Polymers, 28, 991 (1987)

11. P. K. Sengupta and S. Krimm, Biopolymers, 24, 1479 (1985).

12. O. Prasad, P. Tandon, V. D. Gupta, and S. Rastogi, Polymers, 36, 3739 (1995)

13. V. D. Gupta, S. Trevino, and H. Boutin, J. Chem. Phys., 48, 3008
(1968).

14. M. V. Krishnan and V. D. Gupta, Chem. Phys. Lett., 6, 231 (1970).

15. M. V. Krishnan and V. D. Gupta, Chem. Phys. Lett., 7, 285 (1970).

16. R. D. Singh and V. D. Gupta, Spectrochim. Acta, 27A, 385 (1971).

17. A. M. Dwivedi and V. D. Gupta, Chem. Phys. Lett., 16, 909 (1972).

18. V. D. Gupta, R. D. Singh, and A. M. Dwivedi, Biopolymers, 12, 1377 (1973).

19. R. B. Srivastava and V. D. Gupta, Biopolymers, 13, 1965 (1974).

20. L. Burman, P. Tandon, V. D. Gupta, S. Rastogi, S. Srivastava, and G. P. Gupta, J. Phys. Soc. Jpn., 64, 327 (1995).

21. A. Gupta, P. Tandon, V. D. Gupta, S. Rastogi, and G. P. Gupta, J. Phys. Soc. Jpn., 64, 315 (1995).

22. L. Burman, P. Tandon, V. D. Gupta, S. Rastogi, and S. Srivastava, Biopolymer, 38, 57 (1996).

23. S. Srivastava, P. Tandon, V. D. Gupta, and S. Rastogi, Polymers, 37, 5401 (1996).

24. D. I. Bower and W. F. Maddams, "The Vibrational Spectroscopy of Polymers," Cambridge University Press, Cambridge, 1989, p 154.

25. E. B. Wilson, J. C. Decius, and P. C. Cross, "Molecular Vibrations: The Theory of Infrared and Raman Vibrational Spectra," Dover Publications, New York, N.Y., 1980.

26. P. W. Higgs, Proc. R. Soc. (London), Ser. A, 220, 472 (1953).

27. Johnson F. Yan, Garret Vanderkoon, and H. A. Scheraga, J. Chem. Phys., 49, 2713 (1968).

28. P. K. Sengupta and S. Krimm, Biopolymers, 23, 1565 (1984).

29. S. Krimm and J. Bandekar, Adv. Protein. Chem., 38, 181 (1986).

30. B. G. Frushour and J. L. Koenig, "Advances in Infrared and Raman Spectroscopy," Vol. 1, Heyden, London, 1975, p 35.

31. J. L. Koenig and P. L. Sutton, Biopolymers, 10, 89 (1971).

32. S. Srivastava, P. Tandon, V. D. Gupta, S. Rastogi, and C. Mehrotra, Polym. J. (Communicated). 